\title{
Greek
}

\section{Andreas Willi}

\section{Introduction}

\subsection{Historical sketch}

Greek is an Indo-European language that has been spoken on the Balkan Peninsula since the 2nd millennium все. Within the language family, correspondences with Indo-Iranian and Armenian, especially in the area of the morphological system, suggest a central group of languages that underwent innovations after other branches including Italic, Celtic, and Germanic had already separated from the original language. On the Balkan Peninsula, Greek must have come into contact with pre-IndoEuropean substrate languages, but traces of them can only be seen in the

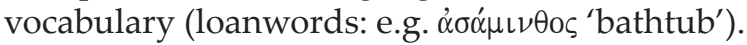

Greek is first attested in writing in the 14th and 13th centuries всЕ in the "Mycenaean" documents primarily from Crete, the Peloponnese, and central Greece. These are administrative texts (lists of tributes, allocations, etc.) written in the syllabic script known as "Linear B," which is predominantly preserved on clay tablets from the Bronze Age palace archives of sites like Knossos, Mycenae, and Thebes. With the mid-20thcentury decipherment of Linear B, Greek became the Indo-European language family attested for the longest stretch of history.

An extensive textual tradition commences, however, only several centuries after the end of the Mycenaean civilization around 1200 вСЕ. Its prerequisite was the takeover of the alphabet from the Northwest Semitic sphere (\$1.2). The earliest, at first still brief, inscriptions date from the 8 th century and are thus approximately contemporary with the recording of the Homeric epics, the Iliad and Odyssey. The latter represent the culmination of a centuries-old tradition of oral poetry, as shown by their stylistic and linguistic form (formulaic verse technique, metrically preserved archaisms). At the same time they constitute the most important reference point for Greek literature in the following centuries until well beyond the Classical period. Thus, epic influences are unmistakable for example in Archaic lyric (7th-5th c.) or 5th-century Athenian tragedy. 
Our earliest extensively preserved prose texts come from the Classical era of the 5th and 4th centuries все. Alongside historians like Herodotus and Thucydides, the Athenian orators (Lysias, Demosthenes, etc.) and philosophers (Plato, Aristotle) are especially important here. Comedy (Aristophanes, Menander) gives us a glimpse of colloquial language, which in view of the nature of the sources is otherwise accessible to us only to a very limited extent through meager inscriptional evidence (graffiti and the like). Papyrus documents referring to everyday matters are not available before the Hellenistic period.

An awareness of the extensive dialectal variety of Greek is indispensable for the cultural understanding of all these texts. Until at least the 4th century every town or region uses its own local dialect, without any one of the dialects being regarded as a general standard. Even so, most literary genres are closely associated with a specific variety. Epic poetry, for instance, is generally Ionic in character, and choral lyric Doric.

On the basis of dialectal isoglosses, only a few of which can be mentioned here, the dialects of the Classical period are divided into four groups: Aeolic, Doric-Northwest Greek, Arcado-Cypriote, and AtticIonic. The first two go back to a northern Greek dialect sphere of the 2nd millennium всE, the others to a southern Greek one. The most important criterion for this distinction is the southern Greek assibilation /ti/ > /si/. By contrast, the change of original (not secondary) /a:/ to / $\varepsilon$ :/ in Attic-

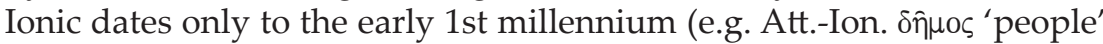
vs. Dor. $\delta \hat{\alpha} \mu \mathrm{o} ;$; cf. §2). Within Attic-Ionic, most characteristic of Attic is the geminate consonant $\tau \tau$ in words like $\theta \dot{\alpha} \lambda \alpha \tau \tau \alpha$ 'sea', where Ionic and other dialects have $\sigma \sigma(\theta \dot{\alpha} \lambda \alpha \sigma \sigma \alpha)$.

During the 5th century вСЕ, Athens established itself as a supraregional power in the Aegean, not least in reaction to the growth of the Persian empire, which was encroaching more and more into regions of Greek settlement in Asia Minor. This development, together with an intensification of inner-Greek trade exchange, led to an increase in dialect contact and mixture. Since Athens at the same time became culturally predominant, Attic spread far beyond its ancestral domain, thereby abandoning its most idiosyncratic traits such as the $\tau \tau$ geminate mentioned above. This "internationalized" Attic is the basis of the "Koine" (i.e., 'common language') into which all the regional dialects gradually merged from the 4th century onward. The Koine tread its own path to victory from the end of that century, in the "Hellenistic" period, with the expansion of the Macedonian empire and its successor states into the Near East and Egypt (Alexandria). By Roman times at the latest, the old local dialects had all but disappeared. Literary and other texts 
were now regularly written in the Koine (e.g., the New Testament, and before it the Septuagint), with a more or less strong orientation towards 5th- and 4th-century Classical Attic depending on the level of education of each author and/or their intended audience. Due to the puristic efforts of the "Atticists," Attic increasingly turned into a linguistic yardstick, and because of the cultural significance of the Classical authors Attic has formed the basis of grammatical descriptions of ancient Greek to this day. The following sketch, too, follows this tradition. In addition, however, important developments in the Hellenistic Koine are highlighted, since Greek entered into the orbit of (Late) Old Testament culture in that period.

\subsection{Script}

Just as each region of Greece in the Archaic and Classical ages had its own dialect (\$1.1), so too did each region have its own distinctive version of the alphabet, which was adapted from the Phoenician alphabet probably in the 9th century. All these "local" ("epichoric") alphabets share the important innovation that some of the Semitic consonant letters were reinterpreted as indispensable vowel symbols. Regional divergences especially concern the newly created supplementary letters added at the end of the alphabet for the phonemes $/ \mathrm{p}^{\mathrm{h}} /, / \mathrm{k}^{\mathrm{h}} /$ and the phoneme sequence /ps/.

The Classical alphabet, which was officially introduced in Athens in $403 / 2$ всE, was originally the epichoric alphabet of the East Ionians of Asia Minor. Characteristic are the addition of $\Omega$ for open $/ \mathrm{s}$ // at the end of the alphabet and the reinterpretation of $\mathrm{H}$ as open $/ \varepsilon: /$ instead of earlier $/ \mathrm{h} /$, which was possible because East Ionic, unlike most of the other dialects, no longer had a phoneme $/ \mathrm{h} /$. After the abandonment of the obsolete letters F (for lost /w/: §2.2) and $\mathrm{Q}$ (for velar $/ \mathrm{k} /$ before back vowels) the following 24 letters were left. Most of them denote individual phonemes, but a few render phoneme sequences $(\mathrm{Z}, \Xi, \Psi)$ (cf. further §2):

$\begin{array}{llllllllllll}\mathrm{A}, \alpha & \mathrm{B}, \beta & \Gamma, \gamma & \Delta, \delta & \mathrm{E}, \varepsilon & \mathrm{Z}, \zeta & \mathrm{H}, \eta & \Theta, \theta & \mathrm{I}, \mathrm{l} & \mathrm{K}, \kappa & \Lambda, \lambda & \mathrm{M}, \mu \\ / \mathrm{a}(:) / & / \mathrm{b} / & / \mathrm{g} / & / \mathrm{d} / & / \mathrm{e} / & / \mathrm{sd} / & / \varepsilon: / & / \mathrm{t}^{\mathrm{h}} / & / \mathrm{i}(:) / & / \mathrm{k} / & / \mathrm{l} / & / \mathrm{m} / \\ \mathrm{N}, \mathrm{v} & \Xi, \xi & \mathrm{O}, \mathrm{o} & \Pi, \pi & \mathrm{P}, \mathrm{\rho} & \Sigma, \sigma / \varsigma & \mathrm{T}, \tau & \mathrm{Y}, \mathrm{v} & \Phi, \Phi & \mathrm{X}, \chi & \Psi, \psi & \Omega, \omega \\ / \mathrm{n} / & / \mathrm{ks} / & / \mathrm{o} / & / \mathrm{p} / & / \mathrm{r} / & / \mathrm{s} / & / \mathrm{t} / & / \ddot{\mathrm{u}}(:) / & / \mathrm{p}^{\mathrm{h}} / & / \mathrm{k}^{\mathrm{h}} / & / \mathrm{ps} / & / \mathrm{s}: /\end{array}$




\section{Phonology}

\subsection{Vowels}

In prehistoric times, Greek had five short and five long vowels $(/ \mathrm{a}(:) /$, /e(:)/, /i(:)/, /o(:)/, /u(:)/). Until the Classical period, the short-vowel system remained relatively stable, except that $/ \mathrm{u} /$ shifted to /ü/ in Attic-Ionic.

The long-vowel system not only underwent the corresponding shift of /u:/ to /ü:/ and - again in Attic-Ionic - the change of inherited /a:/ to / $\varepsilon: /$ $(\S 1.1,3.1 .3)$, but also saw the addition of one back and one front vowel by vowel contraction (after loss of intervocalic consonants like ${ }^{*}-s-$ ) and compensatory lengthening (e.g. $\left.{ }^{*}-V n s^{-}>/-\mathrm{V}: \mathrm{s}-/\right)$. The long vowels /e:/ and /o:/ created in this way were more close than inherited / $\varepsilon: /$ and /o:/, so that (including a similarly created new /a:/) a system with five short and seven long vowels resulted (Table 1). Alongside these twelve vowels there are short and long diphthongs, some of which are likewise inherited, while others (especially among the long diphthongs) arose only within Greek:

$$
\begin{aligned}
& \text { /ai/, /ei/, /oi/, /üi/ (</ui/) } \\
& \text { /au/, /eu/, /ou/ } \\
& \text { /a:i/, /ع:i/, /o:i/ } \\
& \text { (rare) /a:u/, /ع:u/, / :u/ }
\end{aligned}
$$

Graphically, /e:/ appears in Classical orthography as EI and /o:/ as OY. This was made possible by the fact that the original diphthongs /ei/ and /ou/, which had always been written EI and OY, monophthongized early to /e:/ and /o:/ respectively, merging with the secondary long vowels. The more open (old) long vowels $/ \varepsilon: /$ and $/ \mathrm{s}: /$, on the other hand, were written with $H$ and $\Omega(\S 1.2)$.

Possibly as a result of the /u:/ > /ü:/ shift, probably already in the 5th century, the new long vowel /o:/ developed into /u:/, so that the long vowels were better distributed on the back axis. There was no corresponding shift in the short vowels, because there was only one $o$-vowel there.

Table 1. Classical Greek vowels

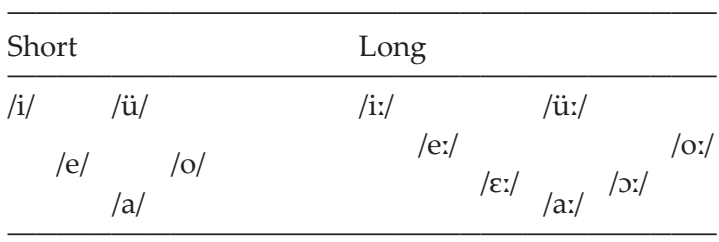


Since on the front axis /i:/ remained unchanged, here there was no empty slot that could have been filled by /e:/. Nevertheless in the 4th century at the latest, /e:/ was raised to /i:/, thus merging with original /i:/. At the same time / $\varepsilon: /$ shifted forward, becoming a new /e:/, which ultimately, in the Roman period, likewise became /i:/. Once again a new / $\varepsilon$ :/ arose at the same time, as the previous diphthong /ai/ monophthongized to $/ \varepsilon: /$ (while /oi/ became /ü:/). The Roman period also saw the definitive loss of distinctive vowel quantity, which accompanied the change from pitch accent to stress accent (§2.3). Still later is the change from /ü(:)/ likewise to $/ \mathrm{i}(:) /$, resulting in the Byzantine-Modern Greek vowel system.

For the Hellenistic Koine, then, something like the system in Table 2 can be laid out. The diphthongs /ai/, /oi/, /üi/, /au/, and /eu/ are preserved, while /a:i/, /ع:i/, and /o:i/ have become pure long vowels through loss of their second element. They are still written AI, HI, $\Omega$ I (Byzantine $\alpha$, $\eta$, $\omega$ with "ı subscript"), but the pronunciation is now /a:/, /e:/, /o:/.

\subsection{Consonants}

During the Classical period the phonological system of Attic included the consonants shown in Table 3. Consonantal /w/, which in earlier times is still attested in various dialects (spelled F), disappeared in the

Table 2. Koine Greek vowels and orthography

\begin{tabular}{|c|c|c|c|c|c|c|}
\hline \multicolumn{2}{|l|}{ Short } & \multicolumn{5}{|l|}{ Long } \\
\hline /i/ & /ü/ & /i:/ & & /ü:/ & & /u:/ \\
\hline I & $\mathrm{Y}$ & I, EI & & $\mathrm{Y}$ & & OY \\
\hline /e/ & /o/ & & le:/ & & lo:/ & \\
\hline $\mathrm{E}$ & $\mathrm{O}$ & & $\mathrm{H}$ & & $\Omega$ & \\
\hline & la/ & & & /a:/ & & \\
\hline
\end{tabular}

Table 3. Classical Greek consonants

\begin{tabular}{ll}
\hline stops & $/ \mathrm{p} /, / \mathrm{t} /, / \mathrm{k} /$ \\
& $/ \mathrm{b} /, / \mathrm{d} /, / \mathrm{g} /$ \\
& $/ \mathrm{p}^{\mathrm{h}} /, / \mathrm{t}^{\mathrm{h}} /, / \mathrm{k}^{\mathrm{h}} /$ \\
nasals & $/ \mathrm{m} /, / \mathrm{n} /$ \\
liquids & $/ \mathrm{l} /, / \mathrm{r} /$ \\
fricatives & $/ \mathrm{s} /, / \mathrm{h} /$ \\
\hline
\end{tabular}


prehistory of Attic-Ionic, albeit later than its counterpart /y/; $/ \mathrm{w} /$ and $/ \mathrm{y} /$ were preserved only as the second component of diphthongs.

The stops comprise a labial, a dental (alveolar), and a velar series, each with a voiceless, voiced, and voiceless aspirated representative. Only in the Late Hellenistic and Roman period did the voiceless aspirates $/ \mathrm{p}^{\mathrm{h}} /, / \mathrm{t}^{\mathrm{h}} /, / \mathrm{k}^{\mathrm{h}} /(\sim \Phi, \Theta, \mathrm{X})$ become fricatives $(/ \mathrm{f} /, / \theta /, / \mathrm{x} /)$. Also late, but difficult to date, is the shift of the voiced stops to voiced fricatives $(/ \mathrm{b} /$, $/ \mathrm{d} /, / \mathrm{g} /(\sim \mathrm{B}, \Delta, \Gamma)>/ \mathrm{v} /, / \mathrm{d} /, / \mathrm{\gamma} /)$.

In addition to the labial and dental nasals with their own letters $(M$, $\mathrm{N})$ there is a velar nasal [n]. Since this occurs only for $/ \mathrm{n} /$ before a velar and possibly for a velar before $/ \mathrm{m} /$ (spelled $Г \Gamma, \Gamma K, \Gamma \mathrm{X}$, or $\Gamma \mathrm{M})$, it does not have phonemic status.

Likewise, the word-initial voiceless pronunciation of the normally voiced / $\mathrm{r} /$ is only allophonic; since Byzantine times it is graphically reflected by writing $\mathrm{P}$ with a spiritus asper ("rough breathing," 'P, $\dot{\rho}$; cf. below), whereas early inscriptions occasionally show $\mathrm{PH}$.

The phoneme /s/ is realized as [z] before voiced sounds. For the letter Z, a bi-phonemic pronunciation [zd] (rather than [dz]) is likely until the Classical period. Some time in the 4th century this must have been simplified to $[\mathrm{z}(\mathrm{z})]$, so that $/ \mathrm{z} /$ too acquired phonemic status in Hellenistic Greek.

Finally, the glottal fricative / h/ occurs only word-initially and in compound forms (e.g. €ühopко /eu-horkos/). While its loss in individual dialects such as East Ionic occurred early ("psilosis"), /h/ persists in the Koine well into the Roman period. However, as soon as the letter $\mathrm{H}$ came to be used for $/ \varepsilon: /$ and no longer designated $/ \mathrm{h} /(\S 1.2)$, the latter sound was no longer written, until the Alexandrian grammarians developed the spiritus asper from an epigraphic variant of $\mathrm{H}$, namely $F$ (' in $\dot{\alpha}$-, $\dot{\epsilon}$ - etc.).

Nasals, liquids, (voiceless) stops, and /s/ can also be geminated; the voiceless aspirated geminated stops are written $\Pi \Phi, \mathrm{T} \Theta, \mathrm{KX}$, with only the second element aspirated.

\subsection{Accent}

Until the Hellenistic period, Greek did not have a stress (intensity, loudness) accent, but a pitch (frequency) accent. This accent can fall on one of the last three syllables of a word if its last syllable is short (i.e. contains a short vowel) or on one of the last two syllables if the last one is long (i.e. contains a long vowel or a diphthong); the placement of the accent for each word is determined paradigmatically. Accents are written in papyri since the Alexandrian period, but systematically only later. 
The acute accent marks high tone on a short vowel or a tone that rises over the duration of a long vowel/diphthong (nom. $\dot{\alpha} \gamma \alpha \theta$ ós). Its counterpart is the circumflex, which marks a tone that falls over the duration of a long vowel/diphthong (and cannot occur on a short vowel) (gen. $\dot{\alpha} \gamma \alpha \theta$ ov̂). The grave accent replaces the acute when the acute would fall on the last syllable of a word that is followed neither by a toneless (enclitic) word nor by a pause (e.g. at the end of a clause) (nom. $\dot{\alpha} \gamma \alpha \theta \dot{o} \varsigma \dot{\alpha} \nu \eta \dot{\rho})$. Enclitic, and so without their own accent, are numerous particles, unstressed pronouns (§3.3.5), or forms of the auxiliary verb $\epsilon^{\prime} \mu \mu^{\prime}$ 'to be' (§3.5.2).

\section{Morphology}

\subsection{Nouns}

\subsubsection{General}

The declension of nouns includes five cases (nominative, genitive, dative, accusative, vocative), three numbers (singular, plural, dual), and three genders (masculine, feminine, neuter). Traces of a separate instrumental, ablative, and locative are only visible as relics (cf. locative adv.

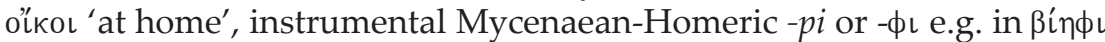
'with force'). The dual, which was lost early in Ionic, survived in Attic until the 4th century, when it disappeared there too. The genders, as in many modern languages, only partly correspond with the biological sex of an item. To be sure, male beings are mostly masculine and female beings feminine, but inanimate and abstract items are far from always neuter, and e.g. diminutives in -เov/-ísıv (\$5) are neuter even when they refer to persons (cf. $\pi \alpha\llcorner\delta$ íov 'child').

Nouns are divided into three declensions according to the final sound of the stem: the first or $\bar{a}$-declension, the second "thematic" or $o$ declension, and the third declension. The $\bar{a}$-declension originally represents a subgroup of the third declension, but in historical times it rather groups with the $o$-declension, as $o$-stem masculines, especially in the adjective paradigm, are regularly paralleled by $\bar{a}$-stem "motionsfeminina"

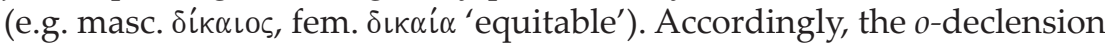
includes primarily masculines and neuters, and the $\bar{a}$-declension feminines, but exceptions do occur (e.g. fem. $\pi \alpha \rho \theta$ '́vos 'maiden'), and within the $\bar{a}$-declension there is even a special masculine type (§3.1.3). Similarly, in the third declension certain formal types are associated with a specific

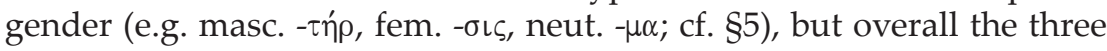
genders are balanced here. 


\subsection{2. $o$-Declension}

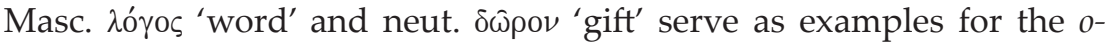
declension. Masculines and neuters are distinguished only in the nominative (and vocative) singular and the nominative and accusative plural. As in all neuter paradigms, the neuter nominative and accusative are identical. In the plural the nominative forms are also used for the vocative (Table 4). Alongside -ols, the dative plural is sometimes -oเol( $\nu$ ) (with or without $-\nu$ ), which predominates in a few non-Attic dialects. A typical feature of Homeric Greek is -oเo for the genitive singular.

Due to some sound changes in Attic-Ionic (esp. - - o- > - $\epsilon \omega-)$, there is a subgroup of the $o$-declension known as the "Attic" declension for words like $\nu \in \omega$ ' ‘ 'temple' (Table 5); because of its irregularity this is lost in Koine Greek.

Table 4. Classical Greek o-declension

\begin{tabular}{|c|c|c|}
\hline & Sg. & Pl. \\
\hline nom. & $\lambda o ́ \gamma-o \zeta(\delta \omega \hat{\rho}-\mathrm{o \nu})$ & $\lambda o ́ \gamma-o \iota(\delta \omega \hat{\rho}-\alpha)$ \\
\hline gen. & $\lambda o ́ \gamma-o v$ & $\lambda o^{\prime} \gamma-\omega \nu$ \\
\hline dat. & $\lambda o ́ \gamma-\omega$ & $\lambda o ́ \gamma-o ı \varsigma$ \\
\hline acc. & $\lambda o^{\prime} \gamma-\mathrm{o \nu}(\delta \hat{\omega} \rho-\mathrm{o \nu})$ & $\lambda$ ó $\gamma$-ous $(\delta \hat{\omega} \rho-\alpha)$ \\
\hline voc. & $\lambda o^{\prime} \gamma-\epsilon(\delta \omega \rho-o \nu)$ & $=$ nom \\
\hline
\end{tabular}

Table 5. Classical Greek "Attic" declension

\begin{tabular}{lll}
\hline & Sg. & Pl. \\
\hline nom. & $\nu \in \dot{\omega} \varsigma$ & $\nu \in \omega^{\prime}$ \\
gen. & $\nu \in \dot{\omega}$ & $\nu \in \omega^{\prime} \nu$ \\
dat. & $\nu \in \dot{\omega}$ & $\nu \in \omega^{\prime} \varsigma$ \\
acc. & $\nu \in \dot{\omega} \nu$ & $\nu \in \omega \dot{\omega} \varsigma$ \\
\hline
\end{tabular}

\subsection{3. $\bar{a}$-Declension}

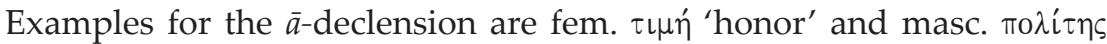
'citizen' (Table 6). Masculines and feminines are distinct in the nominative and genitive singular, where the masculines have taken over $-\varsigma$ and -ov from the $o$-stems; and masculines in - $\tau \varsigma$ have their own vocative 
Table 6. Classical Greek $\bar{a}$-declension

\begin{tabular}{lll}
\hline & Sg. & Pl. \\
\hline nom. & $\tau \iota \mu-\eta^{\prime}(\pi 0 \lambda i \tau-\eta \varsigma)$ & $\tau \iota \mu-\alpha \hat{\imath}$ \\
gen. & $\tau \iota \mu-\hat{\eta} \varsigma(\pi \circ \lambda i \tau-0 \nu)$ & $\tau \iota \mu-\hat{\omega} \nu$ \\
dat. & $\tau \iota \mu-\hat{\eta}$ & $\tau \iota \mu-\alpha \hat{\imath} \varsigma$ \\
acc. & $\tau \iota \mu-\eta^{\prime} \nu$ & $\tau \iota \mu-\bar{\alpha} \varsigma$ \\
voc. & $=$ Nom. $(\pi \circ \lambda \hat{\imath} \tau-\alpha)$ & $=$ Nom. \\
\hline
\end{tabular}

singular. The name " $\bar{a}$-declension" refers to the stem-final original /a:/ that in Attic-Ionic has mostly become / $\varepsilon: /(\$ 2.1)$. In Attic the change generally does not occur after $\epsilon, \iota, \rho$ as in $\chi \omega \omega_{\rho} \bar{\alpha}$ 'land' (gen. $\chi \omega \dot{\omega} \rho \alpha \varsigma$ beside $\tau \iota \mu \eta \hat{\varsigma}$ etc.). Again the dative plural has a variant $-\alpha\llcorner\sigma \iota(v)$ (Homeric $-\eta \sigma \iota(v)$ ) alongside $-\alpha \iota \varsigma$. In the genitive plural the typical stem-final $-\alpha-/-\eta-$ is missing, since $-\hat{\omega} \nu$ is a contraction of $-\bar{\alpha} \omega \nu$.

A subgroup of the $\bar{a}$-declension is formed by the otherwise identically inflected feminines like $\tau \rho \alpha \dot{\alpha} \pi \zeta \alpha^{\prime}$ 'table' with short $-\alpha$ and $-\alpha \nu$ in the nominative and accusative singular. Since most of them involve the old suffix * ${ }^{*} y a$ that can form motionsfeminina from consonant stems, this type is especially common in the feminines of adjectives and participles of the third declension (e.g. fem. $\pi \hat{\alpha} \sigma \alpha$ 'each' < "pant-ya alongside masc. $\pi \hat{\alpha} \varsigma$ with the stem $\pi \alpha \nu \tau-)$.

\subsubsection{Third declension}

According to the stem-final phoneme, the third declension is divided into consonant stems and vowel stems, each with further subgroups $(r$-stems, $i$-stems, $u$-stems, etc.). The case endings are basically identical for all of them, although this fact is occasionally obscured by sound changes. Thus in the accusative singular the $-v$ of the vowel stems and the $-\alpha$ of the consonant stems both go back to prehistoric ${ }^{*} n$ : after a consonant this turned into vocalic ${ }^{*}-n>-\alpha$. Our examples for the consonant stems are the (masculine) $r$-stem $\pi \alpha \tau$ ' $\rho$ 'father', the (feminine) dental

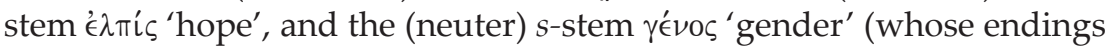
result from vowel contraction after the loss of intervocalic ${ }^{*}$-s-) (Table 7). The example $\pi \alpha \tau \eta \rho p$ shows that, depending on the individual paradigm, the stem can appear in as many as three "ablaut grades" ( $\pi \alpha \tau \eta \rho-, \pi \alpha \tau \in \rho-$, $\pi \alpha \tau \rho(\alpha)-)$. Since the combination of stem-ending $+-\varsigma$ in the nominative singular often results in sound changes (e.g. ${ }^{*}-d-s>-\varsigma$ in ${ }^{\prime} \lambda \pi^{\prime} \zeta$ ), the pure stem can best be seen in the genitive singular. 
Table 7. Classical Greek third declension consonant stems

\begin{tabular}{|c|c|c|c|c|c|}
\hline & & $\begin{array}{l}\text { (Masc.) } r \text {-stem } \\
\text { 'father' }\end{array}$ & $\begin{array}{l}\text { (Fem.) dental } \\
\text { stem 'hope' }\end{array}$ & $\begin{array}{l}\text { (Neut.) s-stem } \\
\text { 'gender' }\end{array}$ & Endings \\
\hline \multirow[t]{5}{*}{ sg. } & nom. & $\pi \alpha \tau \eta \dot{\rho} \rho$ & $\dot{\epsilon} \lambda \pi i \varsigma$ & $\gamma^{\prime} \in \mathcal{\nu} O \varsigma$ & $-\varsigma /-\varnothing$ (neut. -Ø) \\
\hline & gen. & $\pi \alpha \tau \rho-o ́ \varsigma$ & $\mathfrak{\epsilon}^{\prime} \lambda \pi i \delta-O \zeta$ & $\gamma^{\prime} \in \operatorname{\nu ous}\left(<{ }^{*}\right.$-es-os $)$ & $-0 \varsigma$ \\
\hline & dat. & $\pi \alpha \tau \rho-\hat{\imath}$ & $\dot{\epsilon} \lambda \pi^{\prime} \hat{\delta} \delta-\iota$ & $\gamma^{\prime} \in \mathcal{L} \in L\left(<{ }^{*}-e s-i\right)$ & $-\iota$ \\
\hline & acc. & $\pi \alpha \tau \tau^{\prime} \rho-\alpha$ & $\epsilon^{\prime} \lambda \pi^{\prime} \hat{\delta} \delta-\alpha$ & $\gamma^{\prime} \in \mathcal{\nu} O \varsigma$ & $-\alpha$ (neut. $-\varnothing$ ) \\
\hline & voc. & 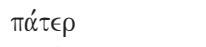 & $=$ nom. & $=$ nom & $-\varnothing($ or = nom.) \\
\hline \multirow[t]{4}{*}{ pl. } & nom./voc. & $\pi \alpha \tau^{\prime} \rho-\epsilon \varsigma$ & $\dot{\epsilon}^{\prime} \lambda \pi i^{\prime} \delta-\epsilon \zeta$ & $\gamma^{\prime} \in \nu \eta\left(<{ }^{*}-e s-a\right)$ & $-\epsilon \varsigma$ (neut. $-\alpha)$ \\
\hline & gen. & 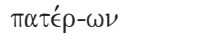 & $\epsilon^{\prime} \lambda \pi i^{\prime} \delta-\omega \nu$ & $\gamma \in \nu \hat{\omega} \nu\left(<{ }^{*}-e s-\bar{o} n\right)$ & $-\omega \nu$ \\
\hline & dat. & $\pi \alpha \tau \rho \alpha^{\prime}-\sigma \iota$ & $\dot{\epsilon} \lambda \pi^{\prime} \hat{L}-\sigma \iota$ & $\gamma^{\prime} \in \in \in \sigma \iota\left(<^{*}-e s-s i\right)$ & $-\sigma \iota(\nu)$ \\
\hline & acc. & $\pi \alpha \tau \tau^{\prime} \rho-\alpha \varsigma$ & $\epsilon \lambda \lambda \pi^{\prime} \delta-\alpha \varsigma$ & $\gamma^{\prime} \in \bar{\nu}\left(<{ }^{*}-e s-a\right)$ & $-\alpha \varsigma$ (neut. $-\alpha$ ) \\
\hline
\end{tabular}

The model paradigms for the vowel stems are the (feminine) $i$-stem

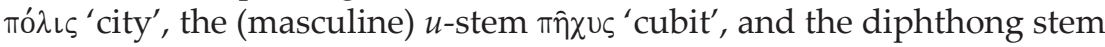
$\beta \alpha \sigma L \lambda \in v^{\prime} \varsigma^{\prime}$ 'king'. The original situation is obscured here, too, by the loss of intervocalic ${ }^{*}-y$ - $\left(i\right.$-stems) or ${ }^{*}-w$-. Moreover Attic in particular has undergone some profound changes (while other dialects display, for example, the more transparent nó $\lambda_{l}-o \zeta$ in the gen. sg.).

In the later Koine the accusatives in $-\alpha$ were often clarified into $-\alpha \nu$, and the accusative plural was harmonized with the nominative plural where the two had still differed in Classical Greek (i.e. $-\epsilon \varsigma$ for $-\alpha \varsigma$ ).

Table 8. Classical Greek third-declension vowel stems

\begin{tabular}{|c|c|c|c|c|c|}
\hline & & $\begin{array}{l}\text { (Fem.) i-stem } \\
\text { 'city' }\end{array}$ & $\begin{array}{l}\text { (Masc.) u-stem } \\
\text { 'cubit' }\end{array}$ & $\begin{array}{l}\text { Diphthong } \\
\text { stem 'king' }\end{array}$ & Endings \\
\hline \multirow[t]{5}{*}{ sg. } & nom. & $\pi o ́ \lambda l-\varsigma$ & $\pi \eta \hat{\chi} \chi U-\varsigma$ & $\beta \alpha \sigma \iota \lambda \in \mathcal{U}^{\prime}-\varsigma$ & -६/-Ø (neut. -Ø) \\
\hline & gen. & 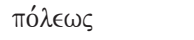 & $\pi \eta^{\prime} \chi \in \omega \varsigma$ & $\beta \alpha \sigma\left\llcorner\lambda \epsilon^{\prime} \omega \varsigma\left(<{ }^{*}-\bar{e} w-O S\right)\right.$ & $-0 \varsigma$ \\
\hline & dat. & $\pi o ́ \lambda \in l$ & $\pi \dot{\eta} \chi \in \mathrm{l}$ & $\beta \alpha \sigma \iota \lambda \in \hat{\imath} \quad\left(<{ }^{*}-\bar{e} w-i\right)$ & $-l$ \\
\hline & acc. & $\pi \lambda^{\prime} \lambda-\nu$ & 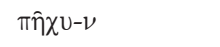 & $\beta \alpha \sigma\left\llcorner\lambda \epsilon^{\prime}-\bar{\alpha} \quad\left(<{ }^{*}-\bar{e} w-a\right)\right.$ & $-\nu /-\alpha$ (neut. $-\varnothing$ ) \\
\hline & voc. & 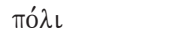 & $\pi \hat{\eta} \chi u$ & $\beta \alpha \sigma \iota \lambda \in \hat{v}$ & $-\varnothing$ \\
\hline \multirow[t]{4}{*}{ pl. } & nom./voc. & 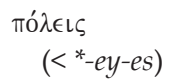 & $\pi \eta^{\prime} \chi \in \iota \varsigma$ & $\begin{array}{l}\beta \alpha \sigma\llcorner\lambda \hat{\eta} \varsigma /-\epsilon \hat{\imath} \varsigma \\
\quad\left(<{ }^{*}-\bar{e} w-e s\right)\end{array}$ & $-\epsilon \varsigma$ (neut. $-\alpha$ ) \\
\hline & gen. & $\pi \lambda^{\prime} \epsilon-\omega \nu$ & $\pi \eta^{\prime} \chi \in-\omega \nu$ & $\begin{array}{l}\beta \alpha \sigma\left\llcorner\lambda \lambda^{\prime}-\omega \nu\right. \\
\quad\left(<{ }^{*}-\bar{e} w-\bar{o} n\right)\end{array}$ & $-\omega \nu$ \\
\hline & dat. & $\pi{ }^{\prime} \lambda \epsilon-\sigma \iota$ & $\pi \dot{\eta} \chi \in-\sigma \iota$ & $\begin{array}{l}\beta \alpha \sigma \iota \lambda \in \hat{U}-\sigma \iota \\
\quad\left(<^{*}-e u-s i\right)\end{array}$ & $-\sigma \iota(\nu)$ \\
\hline & acc. & $\pi \lambda^{\prime} \lambda \in \iota \varsigma$ & $\pi \eta^{\prime} \chi \in \iota \varsigma$ & $\begin{array}{l}\beta \alpha \sigma\left\llcorner\lambda \epsilon^{\prime}-\bar{\alpha} \varsigma\right. \\
\quad\left(<{ }^{*}-\bar{e} w-a s\right)\end{array}$ & $-(\alpha) \varsigma$ (neut. $-\alpha)$ \\
\hline
\end{tabular}




\subsection{Adjectives}

The declension of the adjectives corresponds for the most part to that of the nouns. As a counterpart to $o$-stem masculines and neuters we find $\bar{a}$-stem feminines (§3.1.1), but in compounds separate feminine forms occur with some frequency only in post-Classical times.

In addition to the basic form there are a comparative and a superla-

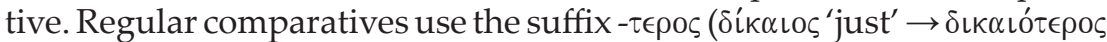
'more just'), but many lexemes have instead an older formation with $-(i) \omega \nu$ (neut. -(i)ov) ( $\kappa \alpha \lambda o ́ \varsigma$ 'beautiful' $\rightarrow \kappa \alpha \lambda \lambda i \omega \nu$ 'more beautiful'). This is inflected as an $n$-stem, but in the accusative singular masculine and feminine and in the nominative and accusative plural (all genders) there are also archaic $s$-stem forms $(-(i) \omega$ and -(i)ous instead of $-(i) o v \alpha$ and $-(\hat{\imath}) o v \in \varsigma /-(\hat{\imath}) \circ \alpha \alpha \varsigma)$.

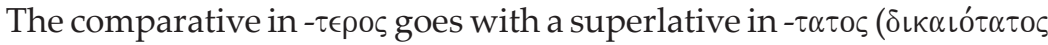
'most just', also elative 'very just'), the comparative in -( $(\mathbf{l}) \omega v$ with a su-

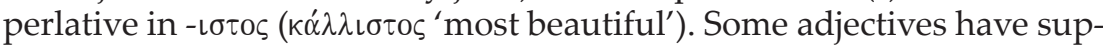
pletive forms of comparison (i.e. comparatives and superlatives from

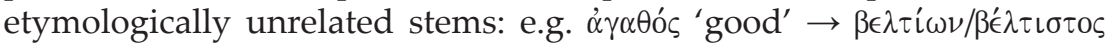
'better/best'). In the Koine the use of the superlative decreases, and the comparative then functions also as superlative/elative.

\subsection{Pronouns}

\subsubsection{Article}

The definite article $\dot{o}, \dot{\eta}$, $\tau$ ó goes back to an old demonstrative pronoun. Its oblique cases are formed from a stem $\tau 0-/ \tau \eta$ - and are inflected like

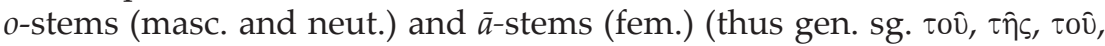
etc.). A stem without the initial dental appears not only in the nominative singular masculine and feminine, but also in the nominative plural (oi, $\alpha i$, but neut. $\tau \dot{\alpha}$ ).

The article precedes its head. If there is a modifier, it comes either in between, or else with repetition of the article after the head ( $\dot{0}$

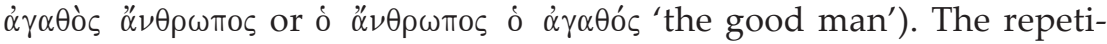
tion is often suppressed, however, with attributive genitives ( $\dot{o} \beta \omega \mu \mathrm{òs}$ $\tau \hat{\omega} v \theta \epsilon \hat{\omega} v$ 'the altar of the gods'). The article is also used on familiar or recently mentioned proper names (o $\Sigma \omega \kappa \rho \alpha ́ t \eta \varsigma)$ and in combination with demonstrative pronouns (\$3.3.2). By contrast, it is not used on predicate nominals. 
Greek does not have an indefinite article. Indefiniteness can be signaled with the indefinite pronoun $\tau \iota \varsigma, \tau \iota$, and later also with the number $\epsilon \hat{i} \varsigma, \mu i \alpha, "$ є $\nu$ 'one' (§3.4).

\subsubsection{Demonstrative pronouns}

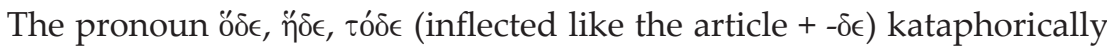
points forward and is used for near deixis ('this here'). However, in post-

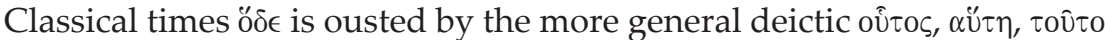

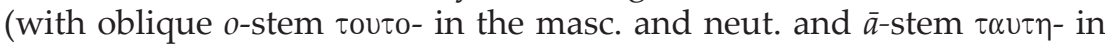
the fem., but nom.pl. oîtol, $\alpha \hat{i} \tau \alpha \iota, \tau \alpha \hat{\tau} \tau \alpha)$, which regularly points back to something that has been mentioned ('this') and may sometimes, but not always, be assigned to middle deixis. Far deixis is signaled by

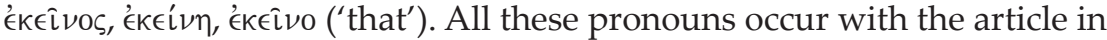

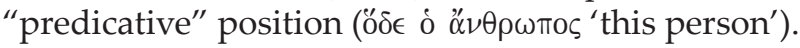

\subsubsection{Relative pronouns}

The simple relative pronoun is ős, $\ddot{\eta}, \ddot{o}$, which takes the inflection of the $o$-stems and $\bar{a}$-stems respectively (gen. sg. oî, $\hat{\eta} s$, oî, etc.). In addition, there is an indefinite generalizing relative pronoun ö $\tau \tau \iota \varsigma$, ท̆ $\tau \iota \varsigma$, ö $\tau$ ' 'who/ whatever', a compound of ö $\varsigma, " \dddot{\eta}$, o + indefinite $\tau \iota \varsigma, \tau \iota$ ( $\$ 3.3 .4$; thus gen. sg.

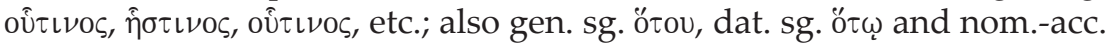
neut. pl. $\ddot{\alpha} \tau \alpha)$. This is also used when the speaker cannot or will not fur-

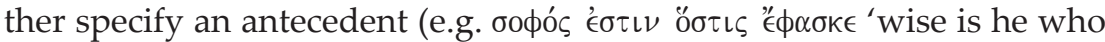

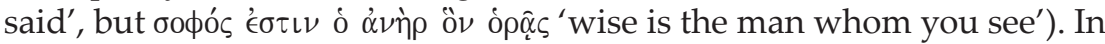

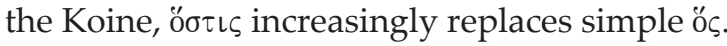

\subsubsection{Interrogative and indefinite pronouns}

The interrogative pronoun masc./fem. $\tau i \varsigma^{\prime}$, neut. $\tau i$ is used substantivally ('who?, what?') and adjectivally ('which?'). In indirect questions ö $\sigma \iota \varsigma$ (§3.3.3) can be used as an alternative. The inflection of $\tau i \varsigma, \tau i$ is based

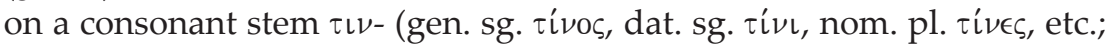
alongside gen. sg. $\tau o \hat{v}$, dat. sg. $\tau \hat{\omega})$.

The indefinite pronoun $\tau \iota \varsigma, \tau \iota$ is formally identical with the interrogative pronoun, except that it is unstressed/enclitic ( $\alpha \nu \theta \rho \omega \pi$ mó $\tau \iota \varsigma$ 'any person', substantivally $\tau \iota \varsigma^{\prime}$ 'someone'). 
The proportion interrogative $\tau i \varsigma$ : indefinite $\tau \iota \varsigma$ : relative ö $\varsigma$ : general-

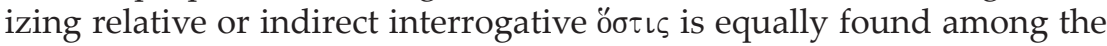
pronominal adverbs; cf. e.g.

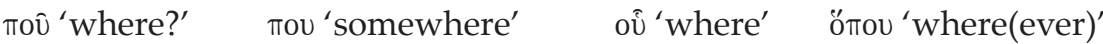

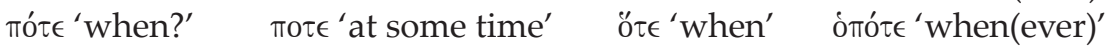

\subsubsection{Personal pronouns}

Personal pronouns (Table 9) are only used in the nominative when they are stressed (e.g. contrastive); elsewhere the person-marking inherent in the verb endings suffices. In the singular each of the other cases has both an enclitic and a stressed form, the latter of which is also used after prepositions.

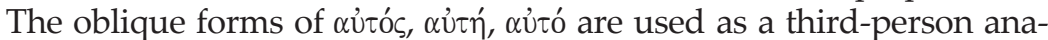
phoric pronoun, which otherwise means 'self/same' (attributive ó aùròs

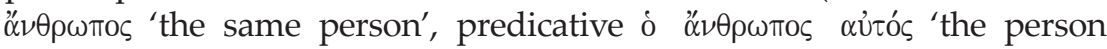
himself').

There are also reflexive pronouns compounded with the stem $\alpha$ ito-

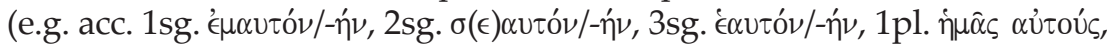

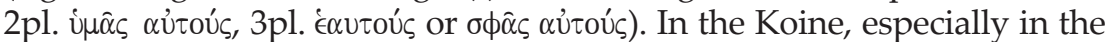

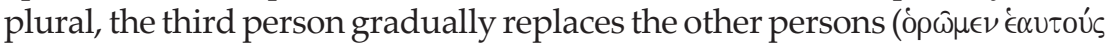

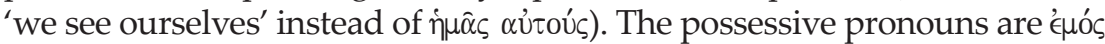

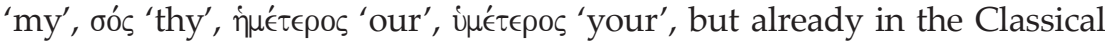
period, and especially later, when unstressed the genitive of the enclitic

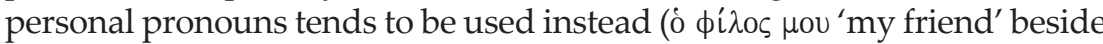

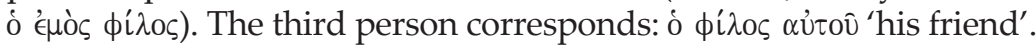

\subsection{Numbers}

Whereas the ordinal numbers inflect as 0 -stem or $\bar{a}$-stem adjectives, the cardinals are declinable only from ' 1 ' to ' 4 ' (also in combinations:

Table 9. Classical Greek personal pronouns

\begin{tabular}{|c|c|c|c|c|}
\hline & \multicolumn{2}{|c|}{ First Person } & \multicolumn{2}{|c|}{ Second Person } \\
\hline & Sg. & Pl. & Sg. & Pl. \\
\hline nom. & $\epsilon^{\prime} \gamma \omega \omega^{\prime}$ & $\dot{\eta} \mu \in \hat{\imath} \varsigma$ & $\sigma u ́$ & $\dot{v} \mu \in \hat{\imath} \varsigma$ \\
\hline gen. & 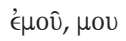 & $\dot{\eta} \mu \omega \hat{\omega} \nu$ & бovิ, бou & $\dot{v} \mu \omega \hat{\omega} \nu$ \\
\hline dat. & 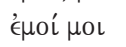 & $\dot{\eta} \mu \hat{\imath} \nu$ & 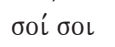 & $\dot{\mathrm{\nu} \mu \mathrm{\iota} \nu}$ \\
\hline acc. & $e^{\prime} \mu{ }^{\prime} \epsilon \epsilon$ & $\dot{\eta} \mu \hat{\alpha} \varsigma$ & $\sigma \epsilon \in$ & $\dot{u} \mu \hat{\alpha} \varsigma$ \\
\hline
\end{tabular}


Table 10. Classical Greek numbers

\begin{tabular}{|c|c|c|}
\hline & Cardinals & Ordinals \\
\hline ' 1 ' & 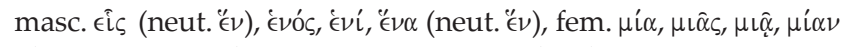 & $\pi \rho \hat{\tau} \tau \sigma \varsigma$ \\
\hline '2' & 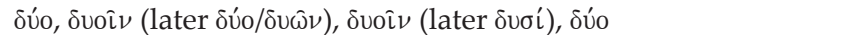 & $\delta \in U ́ \tau \epsilon \rho \circ \varsigma$ \\
\hline ‘3’ & 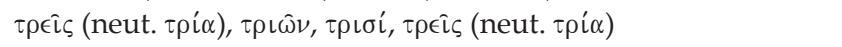 & $\tau \rho \dot{\imath} \tau o \varsigma$ \\
\hline '4’ & $\tau^{\prime} \epsilon \tau \alpha \rho-\epsilon \varsigma$ (neut. $\left.-\alpha\right),-\omega \nu,-\sigma l,-\alpha \zeta$ (neut. $-\alpha$ ) & $\tau \tau^{\prime} \tau \alpha \rho \tau o \varsigma$ \\
\hline ‘5’ & $\pi \epsilon \in \nu \tau \epsilon$ & $\pi \epsilon ́ \mu \pi \tau o \varsigma$ \\
\hline '6’ & " $\xi \xi$ & 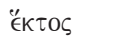 \\
\hline$' 7 ’$ & $\dot{\epsilon} \pi \tau \dot{\alpha}$ & 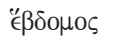 \\
\hline ' 8 ' & 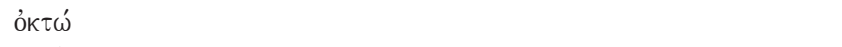 & 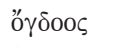 \\
\hline ‘ 9 ' & $\mathfrak{\epsilon}^{\prime} \nu \nu^{\prime} \alpha$ & "'V $\nu \tau \tau$ \\
\hline ' $10^{\prime}$ & $\delta \delta^{\prime} \kappa \alpha$ & 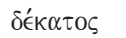 \\
\hline
\end{tabular}

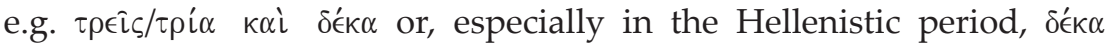

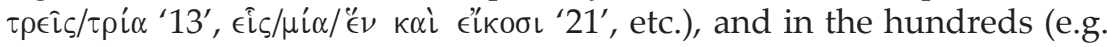
$\delta\left\llcorner\alpha \kappa o ́ \sigma\left\llcorner о \iota /-\alpha \iota /-\alpha\right.\right.$ '200') and thousands (e.g. $\chi^{\prime}(\lambda\llcorner\circ\llcorner/-\alpha \iota /-\alpha$ '1000'). The word for ' 1 ' is unique in distinguishing three genders (Table 10).

\subsection{Verbs}

\subsubsection{General}

The conjugation of the verb is so complex that the presentation here must be especially condensed. Most of the categories can be traced back to the Indo-European proto-language, but Greek has also innovated to an extent (e.g. passive forms) and, post-Classically, restructured or abandoned (e.g. rise of a periphrastic future, loss of the optative and perfect).

There are three persons, three numbers (singular, plural, dual: but on the dual cf. §3.1.1), four moods (indicative, subjunctive, optative, imperative), seven tenses (present, future, imperfect, aorist, perfect, pluperfect, and the rare future perfect), and three voices ("diatheses"; active, middle, passive). The multiplicity of forms is somewhat reduced in that the imperfect and pluperfect appear only in the indicative, the future and future perfect have neither subjunctive nor imperative, the perfect of the subjunctive and optative is mostly periphrastic, and the passive and middle are distinct only in the aorist and future (with the passive expanding in the Koine at the expense of the middle). Also part of the verbal paradigm are (a) an infinitive and a participle in the present, future, aorist, and perfect of each of the voices and (b) one verbal adjec-

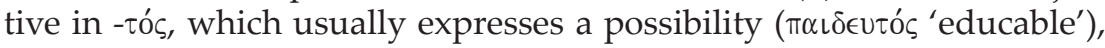




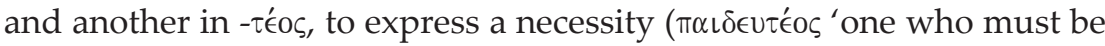
educated').

The verbs are divided into a "thematic" (in - $\omega$ ) and an "athematic" (in $-\mu \iota)$ class. Their endings differ principally in the singular: the stem of the thematic verbs originally ends with an $-\epsilon / 0-$ vowel but synchronically this vowel often merges with the endings proper (cf. $\pi \alpha \iota \delta \in \mathcal{U}^{-}-0-\mu \in \nu$ 'we educate' vs. $\delta \in \mathbf{i} \kappa \nu \nu-\mu \in \nu$ 'we show').

To conjugate a verb one must know its "principal parts," which are derivable only to a limited extent (in entirely regular verbs). These are the present stem, the active and middle future stem, the active and middle aorist stem, the active perfect stem, the mediopassive perfect stem, and the passive aorist stem.

\subsubsection{Present and imperfect}

The thematic and athematic present appear in Table 11A. The athematic presents (of which those in $-\nu \overline{\mathrm{v}} \mu \iota$ constitute the largest group) are much less common than the thematic ones. However, a few frequent verbs are inflected athematically, such as the "root presents" (comprising only root + ending without suffixes) $\epsilon \bar{\imath}-\mu \mathbf{l}^{\prime}$ 'to be' (see below) and $\phi \eta-\mu \mathbf{l}^{\prime}$ 'to say', and the "reduplicated" presents $\delta$ i $-\delta \omega-\mu \iota$ 'to give', $\tau i-\theta \eta-\mu \iota$ 'to put', and ' $-\sigma \tau \eta-\mu \iota$ 'to set up' (with a reduplication syllable containing - - - before the root). Their archaic nature is still seen in the distinct ablaut grades of the

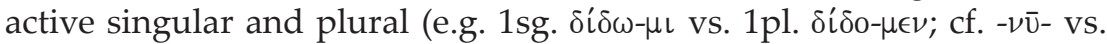
$-\nu \nu$ - in $\delta \epsilon i \kappa \nu \nu \mu \iota)$. Especially in the Hellenistic period, athematic verbs are

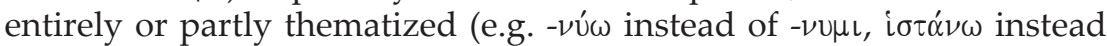

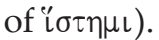

The imperfect is also formed on the present stem (Table 11B). At the front, as in the other past tenses (indicative aorist and pluperfect), comes the "augment," which is realized before a consonant as ' $\epsilon-$, and before an initial vowel as its lengthening (e.g. 'ं $\lambda \pi i \zeta \omega$ 'to hope' $\rightarrow$ imperf.

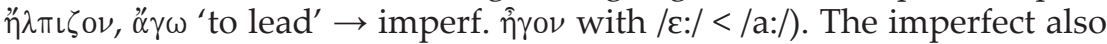
carries the "secondary endings," which originally were distinguished from the "primary endings" of the present only in that they had no final * $i$. Synchronically, however, this relationship is barely recognizable any more. In thematic verbs with vowel-final stems ("contract verbs" in - $-\epsilon$, $-\alpha \omega,-o \omega)$, the result of the contraction of this vowel with the ending is a somewhat distinct inflection that is, however, regular when the relevant contraction rules are taken into account (e.g. $\alpha+\epsilon / \eta=\bar{\alpha}$, thus 3sg. imperf.

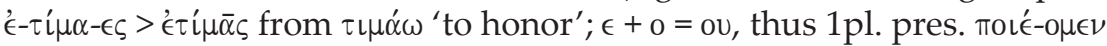

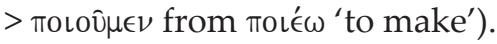


Table 11. Classical Greek present-stem verb inflection

\begin{tabular}{|c|c|c|c|c|c|}
\hline & & \multicolumn{2}{|c|}{ Thematic 'to educate' } & \multicolumn{2}{|c|}{ Aтнематіс 'to show' } \\
\hline & & Active & Middle-passive & Active & Middle-passive \\
\hline \multicolumn{6}{|c|}{ A. Present } \\
\hline \multirow[t]{3}{*}{ sg. } & $1 \mathrm{st}$ & $\pi \alpha\left\llcorner\delta \in U^{\prime}-\omega\right.$ & $\pi \alpha\left\llcorner\delta \in U^{\prime}-о \mu \alpha \iota\right.$ & $\delta \in \epsilon^{\prime} \kappa \nu \overline{\mathrm{U}}-\mu \iota$ & $\delta \in i ́ \kappa \nu v-\mu \alpha \iota$ \\
\hline & 2nd & $\pi \alpha\left\llcorner\delta \in U^{\prime}-\epsilon \iota \varsigma\right.$ & 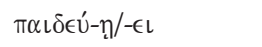 & $\delta \in i ́ \kappa \nu \overline{\mathrm{v}}-\varsigma$ & $\delta \in i ́ \kappa \nu v-\sigma \alpha \iota$ \\
\hline & 3rd & $\pi \alpha \iota \delta \in \dot{U}-\epsilon \iota$ & $\pi \alpha\left\llcorner\delta \in \cup^{\prime}-\epsilon \tau \alpha \iota\right.$ & $\delta \in \hat{L} \kappa \nu \overline{\mathrm{v}}-\sigma \iota(\nu)$ & $\delta \in i ́ \kappa \nu U-\tau \alpha \iota$ \\
\hline \multirow[t]{3}{*}{ pl. } & $1 \mathrm{st}$ & $\pi \alpha\left\llcorner\delta \in v^{\prime}-o \mu \in \nu\right.$ & $\pi \alpha\llcorner\delta \in \mathrm{U}-o ́ \mu \in \theta \alpha$ & $\delta \epsilon i ́ \kappa \nu v-\mu \epsilon \nu$ & $\delta \in \iota \kappa \nu v^{\prime}-\mu \in \theta \alpha$ \\
\hline & 2nd & $\pi \alpha\left\llcorner\delta \in U^{\prime}-\epsilon \tau \epsilon\right.$ & $\pi \alpha\left\llcorner\delta \in \cup^{\prime}-\epsilon \sigma \theta \epsilon\right.$ & $\delta \epsilon i ́ k \nu U-\tau \epsilon$ & $\delta \epsilon i ́ \kappa \nu U-\sigma \theta \epsilon$ \\
\hline & $3 r d$ & $\pi \alpha\left\llcorner\delta \in \cup^{\prime}-\mathrm{ou \sigma} \iota(\nu)\right.$ & $\pi \alpha\left\llcorner\delta \in U^{\prime}-0 \nu \tau \alpha \iota\right.$ & $\delta \in \iota \kappa \nu u^{\prime}-\bar{\alpha} \sigma \iota(\nu)$ & $\delta \in \dot{\epsilon} \kappa \nu \nu-\nu \tau \alpha \iota$ \\
\hline \multirow{4}{*}{$\begin{array}{l}\text { int. } \\
\text { part. }\end{array}$} & & $\pi \alpha\left\llcorner\delta \in \mathcal{U}^{\prime}-\epsilon \iota \nu\right.$ & $\pi \alpha\left\llcorner\delta \in \mathcal{U}^{\prime}-\epsilon \sigma \theta \alpha \iota\right.$ & $\delta \in \iota \kappa \nu{ }^{\prime}-\nu \alpha \iota$ & $\delta \in \epsilon^{\prime} \kappa \nu \nu-\sigma \theta \alpha \iota$ \\
\hline & masc. & $\pi \alpha\left\llcorner\delta \in \mathcal{U}^{\prime}-\omega \nu,-0 \nu \tau O \zeta\right.$ & $\pi \alpha\llcorner\delta \in \mathrm{U}-\mathrm{o} \mu \epsilon \nu \circ \varsigma$ & $\delta \in \iota \kappa \nu \overline{\mathrm{v}}-\varsigma,-\nu \tau O \varsigma$ & $\delta \in \iota \kappa \nu u^{\prime}-\mu \in \nu \circ \varsigma$ \\
\hline & fem. & 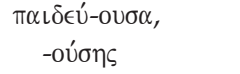 & $\pi \alpha\left\llcorner\delta \in \mathrm{U}-\mathrm{O} \mu \mathbf{H}^{\prime} \nu \eta\right.$ & $\delta \in \iota \kappa \nu \bar{v}-\sigma \alpha,-\sigma \eta \varsigma$ & 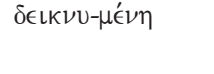 \\
\hline & neut. & $\pi \alpha\llcorner\delta \in \hat{\mathrm{v}}-\mathrm{o \nu},-\mathrm{o \nu} \tau \mathrm{s} \varsigma$ & $\pi \alpha\llcorner\delta \in \mathrm{L}-o ́ \mu \epsilon \nu 0 \nu$ & $\delta \in \iota \kappa \nu u^{\prime}-\nu,-\nu \tau 0 \varsigma$ & $\delta \in \iota \kappa \nu v^{\prime}-\mu \epsilon \nu \mathrm{O} \nu$ \\
\hline \multicolumn{6}{|c|}{ B. IMPERFECT } \\
\hline \multirow[t]{3}{*}{ sg. } & $1 \mathrm{st}$ & $\epsilon-\pi \alpha \hat{\prime} \delta \in \mathrm{U}-\mathrm{O} \nu$ & 'є- $-\alpha\llcorner\delta \in U-o ́ \mu \eta \nu$ & $\epsilon^{\prime}-\delta \epsilon i \kappa \nu \overline{\mathrm{u}}-\nu$ & $\mathfrak{\epsilon}^{\prime}-\delta \epsilon \iota \kappa \nu v^{\prime}-\mu \eta \nu$ \\
\hline & 2nd & $\epsilon-\pi \alpha \mathfrak{\prime} \delta \in U-\epsilon \zeta$ & $\grave{\epsilon}-\pi \alpha \iota \delta \in \dot{u}^{\prime}-\mathrm{ou}$ & $\epsilon_{\epsilon}-\delta \epsilon \dot{\epsilon} \kappa \nu \overline{\mathrm{U}}-\varsigma$ & $\dot{\epsilon}-\delta \in \epsilon^{i} \kappa \nu \mathrm{u}-\sigma o$ \\
\hline & $3 \mathrm{rd}$ & $\epsilon-\pi \alpha \hat{\prime} \delta \in U-\epsilon(\nu)$ & $\mathfrak{\epsilon}^{\prime}-\pi \alpha\llcorner\delta \in \dot{U}-\epsilon \tau 0$ & $\stackrel{\epsilon}{\epsilon}-\delta \epsilon \dot{L} \kappa \nu \overline{\mathrm{U}}$ & $\epsilon-\delta \in \epsilon^{\prime} \kappa \nu \nu-\tau o$ \\
\hline \multirow[t]{3}{*}{ pl. } & 1 st & $\epsilon-\pi \alpha\left\llcorner\delta \in v^{\prime}-o \mu \epsilon \nu\right.$ & ${ }^{\prime}-\pi \alpha\llcorner\delta \in \mathrm{v}-\mathrm{o} \mu \epsilon \Theta \alpha$ & $\epsilon-\delta \epsilon i \kappa \nu \nu-\mu \epsilon \nu$ & $\epsilon-\delta \in \mathrm{L} \nu \mathcal{u}^{\prime}-\mu \epsilon \theta \alpha$ \\
\hline & 2nd & $\dot{\epsilon}-\pi \alpha\left\llcorner\delta \in v^{\prime}-\epsilon \tau \epsilon\right.$ & $\epsilon_{\epsilon}-\pi \alpha\left\llcorner\delta \in \epsilon^{\prime}-\epsilon \sigma \theta \epsilon\right.$ & $\dot{\epsilon}-\delta \epsilon \epsilon^{\prime} \kappa \nu \nu-\tau \epsilon$ & $\grave{\epsilon}-\delta \epsilon \dot{\imath} \kappa \nu U-\sigma \theta \epsilon$ \\
\hline & $3 \mathrm{rd}$ & $\epsilon-\pi \alpha i \delta \in U-o \nu$ & $\grave{\epsilon}-\pi \alpha\left\llcorner\delta \in \mathcal{U}^{\prime}-0 \nu \tau 0\right.$ & $\stackrel{\epsilon}{\epsilon}-\delta \in \epsilon^{\prime} \kappa \nu \nu-\sigma \alpha \nu$ & $\stackrel{\epsilon}{\epsilon}-\delta \in \epsilon^{\prime} \kappa \nu \nu-\nu \tau 0$ \\
\hline \multicolumn{6}{|c|}{ C. Imperative } \\
\hline \multirow[t]{2}{*}{ sg. } & 2nd & $\pi \alpha i \delta \in \mathrm{U}-\epsilon$ & $\pi \alpha\left\llcorner\delta \in U^{\prime}-O U\right.$ & $\delta \in i ́ \kappa \nu \bar{u}$ & $\delta \in i ́ \kappa \nu U-\sigma o$ \\
\hline & $3 \mathrm{rd}$ & $\pi \alpha \iota \delta \in \mathrm{U}-\epsilon \epsilon \omega$ & $\pi \alpha\llcorner\delta \epsilon \cup-\epsilon ́ \sigma \theta \omega$ & $\delta \in \iota \kappa \nu u^{\prime}-\tau \omega$ & $\delta \in \iota \kappa \nu u^{\prime}-\sigma \theta \omega$ \\
\hline \multirow[t]{2}{*}{ pl. } & 2nd & $\pi \alpha\left\llcorner\delta \in \dot{U}^{\prime}-\epsilon \tau \epsilon\right.$ & $\pi \alpha\llcorner\delta \in \dot{U}-\epsilon \sigma \theta \epsilon$ & $\delta \epsilon i ́ \kappa \nu \nu-\tau \epsilon$ & $\delta \epsilon i ́ \kappa \nu \cup-\sigma \theta \epsilon$ \\
\hline & $3 \mathrm{rd}$ & $\begin{array}{l}\pi \alpha\llcorner\delta \in U \text {-ó } \nu \tau \omega \nu \\
\quad(\pi \alpha\llcorner\delta \in U-' \epsilon \tau \omega \sigma \alpha \nu)\end{array}$ & $\begin{array}{l}\pi \alpha\llcorner\delta \in \nu-\epsilon ́ \sigma \theta \omega \nu \\
\quad(\pi \alpha\llcorner\delta \in \nu-\epsilon \sigma \theta \omega \sigma \alpha \nu)\end{array}$ & $\delta \epsilon \iota \kappa \nu u^{\prime}-\nu \tau \omega \nu$ & $\delta \in \iota \kappa \nu \mathcal{U}^{\prime}-\sigma \theta \omega \nu$ \\
\hline
\end{tabular}

'to put'

\section{Subjunctive}

\begin{tabular}{|c|c|c|c|c|}
\hline sg. & $\pi \alpha\left\llcorner\delta \in \epsilon^{\prime}-\omega,-\eta\right\rceil \varsigma,-\eta$ & $\begin{array}{l}\pi \alpha \iota \delta \epsilon U^{\prime}-\omega \mu \alpha \iota,-\eta, \\
-\eta \tau \alpha \iota\end{array}$ & $\tau \iota \theta-\hat{\omega},-\underline{n} \varsigma,-\underline{\eta}$ & $\begin{array}{c}\tau \iota \theta-\hat{\omega} \mu \alpha \iota, \\
-\hat{\eta},-\hat{\eta} \tau \alpha \iota\end{array}$ \\
\hline pl. & $\begin{array}{l}\pi \alpha\left\llcorner\delta \epsilon \mathcal{U}^{\prime}-\omega \mu \epsilon \nu^{\prime}\right. \\
-\eta \tau \epsilon,-\omega \sigma(\nu)\end{array}$ & $\begin{array}{r}\pi \alpha \iota \delta \epsilon \nu-\omega \mu \epsilon \epsilon \theta \alpha \\
-\eta \sigma \theta \epsilon,-\omega \nu \tau \alpha \iota\end{array}$ & $\begin{array}{l}\tau \iota \theta-\hat{\omega} \mu \epsilon \nu_{,} \\
\quad-\eta \hat{\tau} \tau,-\hat{\omega} \sigma \iota(\nu)\end{array}$ & $\begin{array}{l}\tau \iota \theta-\omega \dot{\omega} \mu \epsilon \theta \alpha, \\
\quad-\hat{\eta} \sigma \theta \epsilon,-\hat{\omega} \nu \tau \alpha \iota\end{array}$ \\
\hline
\end{tabular}

\section{E. Optative}

\begin{tabular}{|c|c|c|c|c|}
\hline sg. & $\begin{array}{l}\pi \alpha\left\llcorner\delta \in \cup^{\prime}-\mathrm{ol} \mu \mathrm{L},-\mathrm{ol \varsigma},\right. \\
\quad-\mathrm{ol}\end{array}$ & 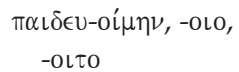 & $\begin{array}{l}\tau \iota \theta-\epsilon i ́ l \mu \eta \nu, \\
-\epsilon \hat{\imath} 0,-\epsilon \hat{\imath} \tau o\end{array}$ & 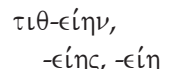 \\
\hline pl. & $\begin{array}{r}\pi \alpha\left\llcorner\delta \in \mathcal{U}^{\prime}-o\llcorner\mu \epsilon \nu\right. \\
-o \iota \tau \epsilon,-o\llcorner\epsilon \nu\end{array}$ & 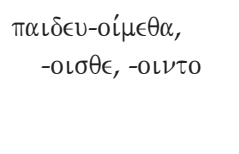 & 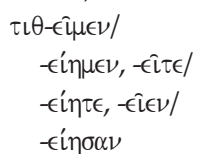 & 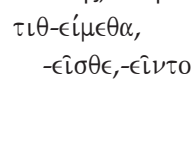 \\
\hline
\end{tabular}


Table 12. Conjugation of $\epsilon i \mu$ í 'to be'

\begin{tabular}{|c|c|c|c|c|c|c|}
\hline & & \multicolumn{2}{|c|}{ INDICATIVE } & \multirow{2}{*}{$\begin{array}{l}\text { Subjunctive } \\
\text { Present }\end{array}$} & \multirow{2}{*}{$\begin{array}{l}\text { Optative } \\
\text { Present }\end{array}$} & \multirow{2}{*}{$\begin{array}{l}\text { IMPERATIVe } \\
\text { Present }\end{array}$} \\
\hline & & Present & Imperfect & & & \\
\hline \multirow[t]{3}{*}{ sg. } & 1st & eíuí & $\hat{\eta} \nu$, older $\hat{\eta}\left(\eta \eta^{\prime} \mu \nu\right)$ & $\hat{\omega}$ & 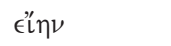 & \\
\hline & 2nd & $\epsilon \hat{i}$ & 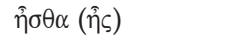 & ทุ่s & Eln & ’ $\sigma \theta_{\iota}$ \\
\hline & $3 r d$ & $\epsilon^{\prime} \sigma \tau \iota^{\prime}$ & $\hat{\eta} \nu$ & ทุ & 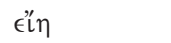 & ${ }^{\prime \prime} \sigma \tau \omega$ \\
\hline \multirow[t]{3}{*}{ pl. } & 1 st & $\dot{\epsilon}^{\prime} \sigma \mu \mu^{\prime} \nu$ & 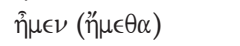 & $\hat{\omega} \mu \in \nu$ & $\epsilon \hat{\imath} \mu \epsilon \nu / \epsilon \prime \eta \eta \mu \epsilon$ & \\
\hline & 2nd & '́⿴囗十 $\tau^{\prime}$ & $\hat{\eta}(\sigma) \tau \epsilon$ & $\hat{\eta} \tau \epsilon$ & $\epsilon i \tau \epsilon / \epsilon " \eta \eta \tau \epsilon$ & 'є́ $\sigma \tau \epsilon$ \\
\hline & 3rd & $\epsilon i \sigma i(v)$ & $\hat{\eta} \sigma \alpha \nu$ & 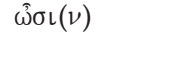 & $\epsilon \tilde{\epsilon} \in \nu / \epsilon " \eta \eta \sigma \alpha \nu$ & 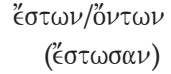 \\
\hline
\end{tabular}

There is an imperative (Table 11C; Hellenistic innovations in parentheses) for the second and third person (e.g. $\pi \alpha\left\llcorner\delta \in \cup \in \epsilon^{\prime} \omega\right.$ 'he must educate!').

The subjunctive (Table 11D) is characterized by long-vowel ("primary") endings, which were transferred from the thematic inflection to the athematic early on. Where the indicative has $-\eta-/-\omega-$ (1sg. act., 2 sg. mid.-pass.), it does not differ from the subjunctive.

The optative, lastly (Table 11E), is marked by a diphthong before the endings (of the "secondary" set, except in the 1sg. act.). Thematic verbs

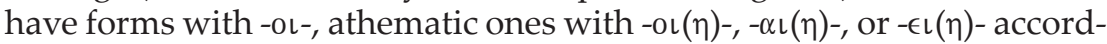
ing to the vowel of the verb root (e.g. $\tau \iota \theta \in i \eta \eta \nu$ 'I would put' from $\tau \iota \theta \in-$,

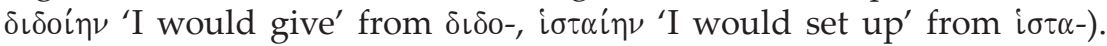
Since the verbs in $-\nu v \mu$ เ have been assimilated to the thematic verbs in the subjunctive and optative (subj. $\delta \in \iota \kappa \nu$ ' $-\omega$, opt. $\left.\delta \epsilon \iota \kappa \nu v^{\prime}-o \iota \mu \iota\right), \tau i \theta \eta \mu \iota$ 'to put' is used here as an example of the athematic inflection. Its subjunctives are again explained by vowel contraction (e.g. 1sg. $\left.\tau \iota \theta \hat{\omega}<{ }^{*} \tau \iota \theta^{\prime} \in-\omega\right)$.

The athematic conjugation of $\epsilon i \mu l^{\prime}$ 'to be' (Table 12) is important (inf.

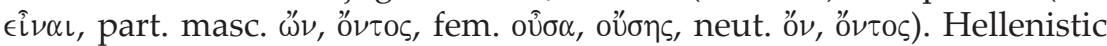
forms, which to an extent prefigure the later transfer of the verb into the middle ( $\left.\epsilon i \mu \mu^{\prime} \rightarrow \epsilon i \tilde{\mu} \alpha \iota\right)$, are again parenthesized.

\subsubsection{Aorist}

In the productive "sigmatic" aorist (Table 13) an element $-\sigma(\alpha)$ - fol-

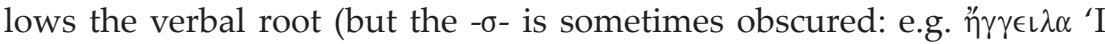
announced' with $-\epsilon \iota \lambda-<^{*}$-els- from the pres. $\left.\dot{\alpha} \gamma \gamma^{\prime} \epsilon \lambda \lambda \omega\right)$. The endings are similar to the thematic secondary endings, but they have $-\alpha$ - in place of $-\epsilon / 0$ - except in the 3sg. active. As an aspectual category (\$4.2.2), the aorist also has (unaugmented) modal forms, infinitives, and participles. The 
Table 13. Classical Greek aorist-stem verb inflection

\begin{tabular}{|c|c|c|c|}
\hline & & Active & Middle \\
\hline \multicolumn{4}{|c|}{ INDICATIVE } \\
\hline \multirow[t]{3}{*}{ sg. } & $1 \mathrm{st}$ & $\hat{\epsilon}-\pi \alpha i \delta \in U-\sigma \alpha$ & $\mathfrak{\epsilon}^{\epsilon}-\pi \alpha\llcorner\delta \epsilon \mathrm{U}-\sigma \alpha \dot{\alpha} \mu \eta \nu$ \\
\hline & 2 nd & $\epsilon-\pi \alpha \hat{i} \delta \in U-\sigma \alpha \varsigma$ & $\grave{\epsilon}-\pi \alpha\left\llcorner\delta \in \epsilon^{\prime}-\sigma \omega\right.$ \\
\hline & $3 r d$ & $\dot{\epsilon}-\pi \alpha i \delta \epsilon \in-\sigma \epsilon(\nu)$ & $\mathfrak{\epsilon}^{\prime}-\pi \alpha\left\llcorner\delta \in \mathcal{U}^{\prime}-\sigma \alpha \tau 0\right.$ \\
\hline \multirow[t]{3}{*}{ pl. } & $1 \mathrm{st}$ & $\stackrel{\epsilon}{\epsilon}-\pi \alpha\left\llcorner\delta \in U^{\prime}-\sigma \alpha \mu \epsilon \nu\right.$ & $\grave{\epsilon}-\pi \alpha\left\llcorner\delta \in \mathrm{U}-\sigma \alpha^{\prime} \mu \epsilon \theta \alpha\right.$ \\
\hline & 2nd & ${ }^{\prime} \epsilon-\pi \alpha\left\llcorner\delta \epsilon v^{\prime}-\sigma \alpha \tau \epsilon\right.$ & $\mathfrak{\epsilon}^{\prime}-\pi \alpha\left\llcorner\delta \epsilon \mathcal{U}^{\prime}-\sigma \alpha \sigma \theta \epsilon\right.$ \\
\hline & $3 \mathrm{rd}$ & $\grave{\epsilon}-\pi \alpha \dot{i} \delta \in \mathrm{U}-\sigma \alpha \nu$ & $\epsilon^{\epsilon}-\pi \alpha\llcorner\delta \epsilon \dot{U}-\sigma \alpha \nu \tau 0$ \\
\hline \multicolumn{4}{|c|}{ IMPERATIVE } \\
\hline \multirow[t]{2}{*}{ sg. } & 2 nd & $\pi \alpha i \delta \in \mathrm{i}-\sigma \mathrm{O \nu}$ & $\pi \alpha i \delta \in U-\sigma \alpha \iota$ \\
\hline & $3 \mathrm{rd}$ & $\pi \alpha\llcorner\delta \epsilon U-\sigma \alpha ́ \alpha \omega$ & $\pi \alpha\llcorner\delta \in \mathrm{U}-\sigma \alpha \dot{\alpha} \sigma \theta \omega$ \\
\hline \multirow[t]{2}{*}{ pl. } & 2nd & $\pi \alpha\left\llcorner\delta \epsilon U^{\prime}-\sigma \alpha \tau \epsilon\right.$ & $\pi \alpha \iota \delta \epsilon \dot{v}-\sigma \alpha \sigma \theta \epsilon$ \\
\hline & 3rd & $\pi \alpha\llcorner\delta \in U-\sigma \alpha \dot{\alpha} \nu \tau \omega \nu(\pi \alpha\llcorner\delta \in U-\sigma \alpha ́ \tau \tau \omega \sigma \alpha \nu)$ & $\pi \alpha\llcorner\delta \epsilon U-\sigma \alpha ́ \sigma \theta \omega \nu(\pi .-\sigma \alpha ́ \sigma \theta \omega \sigma \alpha \nu)$ \\
\hline \multicolumn{2}{|c|}{$\begin{array}{l}\text { Subjunctive } \\
\text { Optative }\end{array}$} & $\pi \alpha\left\llcorner\delta \in \dot{u}^{\prime}-\sigma \omega,-\sigma \eta \preceq\right.$ etc. & $\pi \alpha\left\llcorner\delta \in v^{\prime}-\sigma \omega \mu \alpha \iota,-\sigma \eta \emptyset\right.$ etc. \\
\hline \multicolumn{2}{|c|}{ OPtATIVE } & 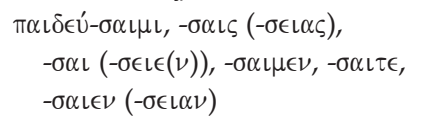 & 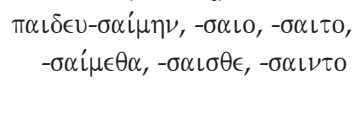 \\
\hline \multicolumn{2}{|c|}{ INFINITIVE } & $\pi \alpha \iota \delta \in \hat{v}-\sigma \alpha \iota$ & $\pi \alpha\left\llcorner\delta \in \mathcal{U}^{\prime}-\sigma \alpha \sigma \theta \alpha \iota\right.$ \\
\hline \multicolumn{4}{|c|}{ Participle } \\
\hline & \multirow{3}{*}{$\begin{array}{l}\text { masc. } \\
\text { fem. } \\
\text { neut. }\end{array}$} & $\pi \alpha\left\llcorner\delta \in \mathcal{U}^{\prime}-\sigma \bar{\alpha} \varsigma_{,},-\sigma \alpha \nu \tau \sigma \varsigma\right.$ & 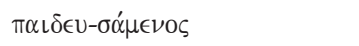 \\
\hline & & $\pi \alpha \iota \delta \in \mathcal{U}^{\prime}-\sigma \bar{\alpha} \sigma \alpha,-\sigma^{\prime} \bar{\alpha} \sigma \eta \zeta$ & $\pi \alpha \iota \delta \in \mathrm{U}-\sigma \alpha \mu \mu^{\prime} \nu \eta$ \\
\hline & & $\pi \alpha \iota \delta \in \hat{v}-\sigma \alpha \nu,-\sigma \alpha \nu \tau 0 \varsigma$ & $\pi \alpha\llcorner\delta \in \nu-\sigma \alpha ́ \alpha \epsilon \nu \nu \nu$ \\
\hline
\end{tabular}

subjunctive endings are identical with those of the present, but otherwise here too, except in the infinitive active and the 2 sg. imperative, the "alpha-thematic" system described above holds. Note that in Attic the parenthesized variants of the optative prevail.

The aorist passive stem (Table 14 ) is marked by $-(\theta) \eta-$, to which in the indicative the active athematic secondary endings are added (without

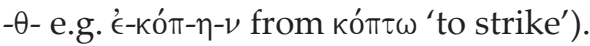

Instead of a sigmatic aorist, many verbs have an (older) thematic or "strong" aorist, whose inflection to a great extent corresponds to that of the thematic imperfect or the non-indicative moods of the present. However, its stem is different from the present stem (e.g. pres. $\beta \dot{\alpha} \lambda \lambda-\omega$ 'to throw' with imperf. "'- $\beta \alpha \lambda \lambda$-ov, but aor. indic. act. " $\epsilon-\beta \alpha \lambda-o \nu$, subj. $\beta \alpha \dot{\alpha} \lambda-\omega$,

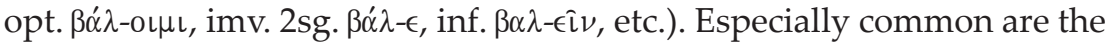

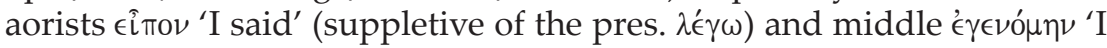

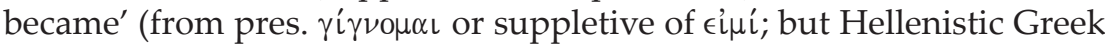
has pass. 'ं $\gamma \in \nu \dot{\eta} \theta \eta \nu$ instead). In later stages of the language, fusion with the "alpha-thematic" inflection is typical (at first 3pl. $\epsilon i \pi \alpha \nu$ in place of

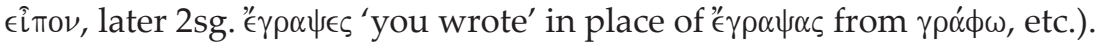


Table 14. Classical Greek aorist passive stem

\begin{tabular}{|c|c|}
\hline $\begin{array}{l}\text { INDICATIVE } \\
\text { SubJunctive } \\
\text { Optative } \\
\text { INFINITIVE } \\
\text { IMPERATIVE }\end{array}$ & 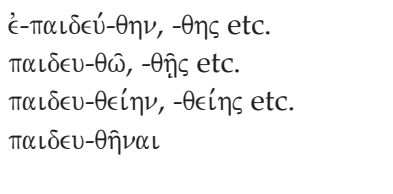 \\
\hline $\begin{array}{l}\text { sg. } \\
\text { pl. }\end{array}$ & $\begin{array}{l}\pi \alpha\left\llcorner\delta \in \mathcal{u}^{\prime}-\theta \eta \tau \iota,-\theta \eta^{\prime} \tau \omega\right. \\
\pi \alpha\left\llcorner\delta \in \mathcal{u}^{\prime}-\theta \eta \tau \epsilon,-\theta^{\prime} \nu \tau \omega \nu\left(-\theta \eta{ }^{\prime} \tau \omega \sigma \alpha \nu\right)\right.\end{array}$ \\
\hline $\begin{array}{l}\text { PARTICIPLE } \\
\text { masc. } \\
\text { fem. } \\
\text { neut. }\end{array}$ & 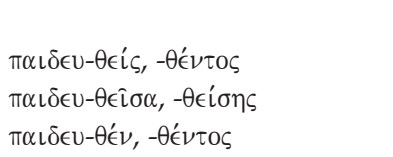 \\
\hline
\end{tabular}

Much rarer are the mostly intransitive "root aorists" (unsuffixed verbal root + ending), whose inflection is similar to that of the passive aorist in $-\theta \eta \nu$ (1sg. indic. ' $€-\beta \eta-\nu$ 'I went', subj. $\beta \hat{\omega}$, opt. $\beta \alpha i \eta \nu$, etc.).

\subsubsection{Future}

The future (Table 15) must have arisen at least in part from an aorist subjunctive. It likewise has the tense marker $-\sigma-$, followed by the thematic (primary) endings.

The formation of the passive generally resembles the passive aorist, with the tense marker $-\sigma$ - combined with $-(\theta) \eta-$. However, it uses middle endings (1sg. $\pi \alpha\llcorner\delta \in v-\theta \eta \dot{\eta}-\sigma \circ \mu \alpha \iota)$, just as elsewhere the future in Classical

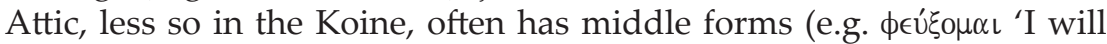

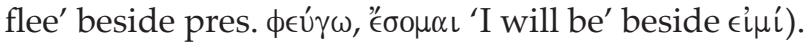

A future without $-\sigma-$, which looks like a present in $-\epsilon \omega$, is found with verb roots ending in liquids or nasals (e.g. $\mu \epsilon \in \omega$ 'to stay', fut. $\mu \in \nu \hat{\omega}$ )

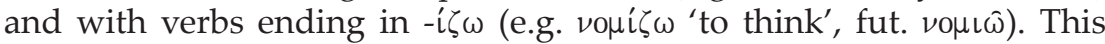
formation originated in roots like $\kappa \alpha \lambda \epsilon-$ 'to call', in which intervocalic

Table 15. Classical Greek future

\begin{tabular}{|c|c|c|}
\hline & Active & Middle \\
\hline INDICATIVE & $\pi \alpha\left\llcorner\delta \in v^{\prime}-\sigma \omega,-\sigma \in\llcorner\varsigma\right.$ etc. & $\pi \alpha\left\llcorner\delta \in U^{\prime}-\sigma o \mu \alpha \iota,-\sigma \eta ̣ /-\sigma \in \iota\right.$ etc. \\
\hline Optative & $\pi \alpha\left\llcorner\delta \in \cup^{\prime}-\sigma o \iota \mu \iota,-\sigma o \iota \varsigma\right.$ etc. & 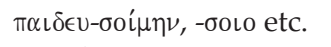 \\
\hline INFINITIVE & $\pi \alpha\left\llcorner\delta \in \mathcal{U}^{\prime}-\sigma \in \iota \nu\right.$ & $\pi \alpha\left\llcorner\delta \in v^{\prime}-\sigma \in \sigma \theta \alpha \iota\right.$ \\
\hline Participle & $\pi \alpha \iota \delta \in \cup^{\prime}-\sigma \omega \nu$ etc. & $\pi \alpha\llcorner\delta \in \mathrm{U}-\sigma o ́ \mu \epsilon \nu \mathrm{o} \varsigma$ etc. \\
\hline
\end{tabular}


- $\sigma$ - regularly disappeared ( $\left.{ }^{*} \kappa \alpha \lambda \lambda^{\prime}-\sigma \omega>\kappa \alpha \lambda \epsilon^{\prime} \omega>\kappa \alpha \lambda \hat{\omega}\right)$ and was not restored as in $\pi \alpha\left\llcorner\delta \in \cup \dot{\sigma} \omega\right.$ (by analogy with cases like $\delta \in \epsilon^{\prime} \xi \omega={ }^{*} \delta \in \dot{\epsilon} \kappa-\sigma \omega$ 'I will show'). The Koine here regularizes ( $\kappa \alpha \lambda^{\prime} \epsilon \omega, \nu$ o $\mu^{\prime} \sigma \omega$, etc.).

\subsubsection{Perfect, pluperfect, and future perfect}

The perfect (Table 16A) has (a) in the active a special set of endings that despite similarities with the alpha-thematic endings of the aorist are different in origin; (b) in the most productive type, and again only in the active, a stem-forming suffix - $\mathrm{k}-$; and (c) throughout a reduplication syllable containing the vowel $-\epsilon-$, in which normally the initial consonant of the root is repeated $\left(C_{x} \in-C_{x} \ldots\right)$. If this is aspirated, the unaspirated counterpart appears (e.g. $\tau \tau^{\prime}-\theta \eta-\kappa \alpha$ 'I have put'). In roots beginning with more than one consonant (except stop plus liquid clusters like $\kappa \lambda-, \delta \rho-)$ or with $\dot{\rho}-$, simple ' $\epsilon$ - is used (e.g. ' with an initial vowel the reduplication syllable is the same as the (lengthened) augment (e.g. $\eta \hat{} \chi \alpha^{\prime}$ I have led' from ' $\alpha \gamma \omega$ ). The reduplicated perfect stem is also found in the future perfect and the pluperfect (the latter still being augmented in Classical times) (Table 16B). In the middle/passive, perfect and pluperfect take the athematic primary and secondary endings respectively. The moods of the perfect and the active future perfect are formed periphrastically with the corresponding forms of $\epsilon i \mu i$ + per-

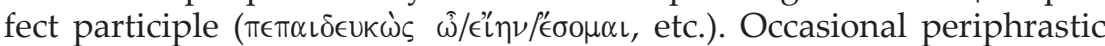
forms also occur elsewhere already in Classical times.

Table 16. Classical Greek perfect and pluperfect

\begin{tabular}{|c|c|}
\hline Active & Middle-Passive \\
\hline \multicolumn{2}{|c|}{ A. Perfect } \\
\hline $\begin{array}{l}\pi \epsilon-\pi \alpha i \delta \epsilon \cup-\kappa \alpha,-\kappa \alpha \varsigma,-\kappa \epsilon(\nu),-\kappa \alpha \mu \epsilon \nu,-\kappa \alpha \tau \epsilon, \\
-\kappa \bar{\alpha} \sigma L(\nu)(\text { later }-\kappa \alpha \nu)\end{array}$ & $\begin{array}{l}\pi \epsilon-\pi \alpha i \delta \in U-\mu \alpha \iota,-\sigma \alpha \iota,-\tau \alpha \iota,-\mu \in \theta \alpha,-\sigma \theta \epsilon, \\
-\nu \tau \alpha \iota\end{array}$ \\
\hline \multicolumn{2}{|l|}{ INFINITIVE } \\
\hline 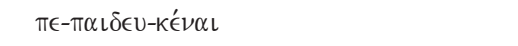 & $\pi \epsilon-\pi \alpha\llcorner\delta \in \hat{\mathrm{v}}-\sigma \theta \alpha \iota$ \\
\hline \multicolumn{2}{|l|}{ PARTiciple } \\
\hline 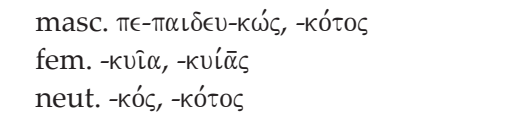 & $\pi \epsilon-\pi \alpha\left\llcorner\delta \epsilon U-\mu \epsilon^{\prime} \nu O \zeta,-\mu{ }^{\prime} \nu \eta,-\mu \epsilon^{\prime} \nu O \nu\right.$ \\
\hline \multicolumn{2}{|c|}{ B. Pluperfect } \\
\hline $\begin{array}{l}\dot{\epsilon}-\pi \epsilon-\pi \alpha\left\llcorner\delta \in \mathcal{U}^{\prime}-\kappa \eta /-\kappa \epsilon \iota \nu,-\kappa \eta \varsigma /-\kappa \epsilon \iota \zeta,-\kappa \epsilon \iota(\nu),\right. \\
\quad-\kappa \epsilon(\iota) \mu \epsilon \nu,-\kappa \epsilon(\iota) \tau \epsilon,-\kappa \epsilon(\iota) \sigma \alpha \nu\end{array}$ & $\begin{array}{l}\epsilon-\pi \epsilon-\pi \alpha\left\llcorner\delta \in \mathcal{U}^{\prime}-\mu \eta \nu,-\sigma o,-\tau 0,-\mu \epsilon \theta \alpha,-\sigma \theta \epsilon,\right. \\
\quad-\nu \tau 0\end{array}$ \\
\hline
\end{tabular}


Roots ending with a dental or guttural do not have a stem-forming suffix -k-; instead these sounds are usually aspirated (e.g. $\tau^{\prime} \in-\tau \alpha \chi-\alpha$ 'I have arranged' from $\tau \alpha \gamma-)$. Other, sometimes very old, intransitive perfects belong to a "strong" type without - $\kappa-$, but with root ablaut (e.g. $\pi \epsilon^{\prime}-\pi \circ \theta^{\prime}-\alpha$ 'I have trusted' from middle pres. $\pi \epsilon i \theta 0 \mu \alpha \iota, \gamma^{\prime} \epsilon-\gamma o \nu-\alpha$ 'I have become' beside

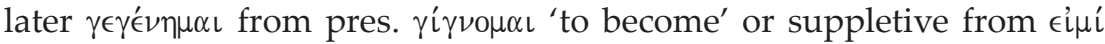
'to be').

\section{Syntax}

\subsection{Case syntax}

The nominative is used for the subject of a clause and for attributes and predicate nominals agreeing with it. The vocative is used for address, often in combination with the particle $\hat{\omega}$.

The accusative stands for the direct object, whether affected (óòv $v$ óóc ' to see a path'), effected (óoòv molé $\omega$ 'to make a path'), or - also with intransitive verbs - an inner object (óò̀v €î $\mu \mathrm{r}$ 'to follow a path'; similarly with substantivized neuter adjectives: $\delta \epsilon \iota \nu \grave{\alpha} i \dot{i} \beta \rho \zeta \zeta \omega$ 'to commit outrageous sacrilege'). Some verbs are construed with double accusative (e.g. $\alpha i \tau \in$ ' $\omega \tau \iota \nu \alpha$ $\tau L^{\prime}$ to ask someone for something'). The accusative further ex-

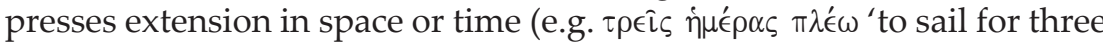
days') and also occurs as a free accusative of relationship with adjectives,

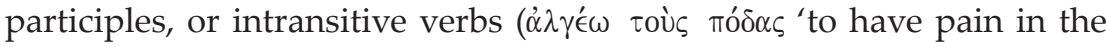

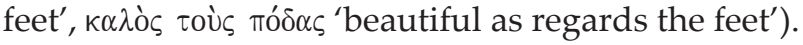

The genitive marks possession in the widest sense (belongings, characteristics, material, etc.: e.g. $\tau \rho\llcorner\hat{\omega} \nu \dot{\eta} \mu \in \rho \hat{\omega} \nu$ óoós 'a journey of three days'), and hence, as a "partitive" genitive, the assemblage/group to which something belongs (e.g. $\tau i \varsigma$ i $\dot{\eta} \mu \omega v$; 'who of us?'; post-Classically $\dot{\epsilon}^{\xi}$ 'out of $^{\prime}+$ gen. instead). The genitive is also partitive with verbs of participating, touching, governing, etc., and with verbs of perception, where Greek likes to emphasize the fact that the object is only partially affected

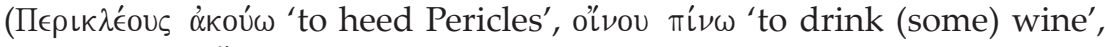

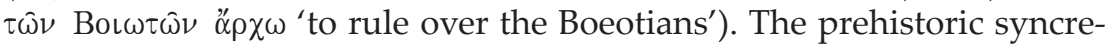
tism of the ablative (\$3.1.1) with the genitive explains the ablatival use of the genitive with verbs of separation (later often $\dot{\alpha} \pi \mathrm{o}^{\prime} / \mathrm{K}^{\prime} \xi$ 'from/out of' + gen.) and in comparisons ( $\kappa \alpha \lambda \lambda i \omega \nu$ immou 'more beautiful than a horse';

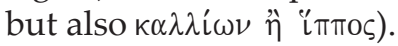

The dative indicates the indirect object, but also occurs as a free dative of advantage ('to do something for someone'). This is the basis of its use for the agent of an action in the passive perfect, while in other tenses 
of the passive the preposition úmó + genitive is usually used instead. Once again because of prehistoric case syncretism, the dative further assumes the functions of the earlier instrumental and locative; to the former be-

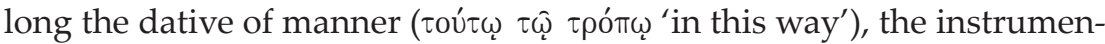
tal dative ( $\lambda i \operatorname{\theta }$ oเs $\beta \alpha \dot{\alpha} \lambda \lambda \omega$ 'to pelt with stones'), and the datives of motive

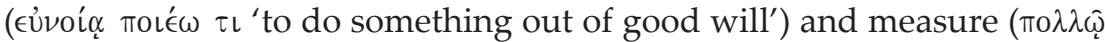
$\kappa \alpha \lambda \lambda i \omega \nu$ 'much more beautiful'); and to the latter the temporal dative ( $\tau \alpha v^{\prime} \eta \underline{n} \tau \hat{\eta} \dot{\eta} \mu \epsilon^{\prime} \rho \alpha$ 'on this day'). Actual locations usually require a preposi-

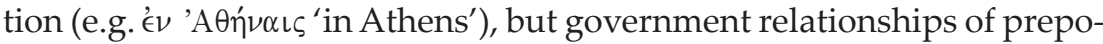
sitions that arose from syntactically free adverbs still reflect the ancestral assignment of cases. Thus "ablatival" prepositions like $\pi \alpha \rho \alpha$ ' from' and ' $\xi \xi$ 'out of' take the genitive, "locatival" prepositions like $\pi \alpha \rho \alpha$ ' at, near' and $\epsilon \nu^{\prime}$ 'in' take the dative, and "directional" ones like $\pi \alpha \rho \alpha$ ' 'along, toward' and $\epsilon i \varsigma^{\prime}$ 'into' take the accusative.

Starting in the Koine, a striking increase in prepositional syntagms can be observed (cf. above on the genitive). This is especially noticeable in the Late Roman-Byzantine period in the dative, which in Modern Greek is replaced by the genitive or by $\epsilon i \zeta+$ accusative. The periphrasis of the instrumental dative with ' $\epsilon$ + dative in Biblical Greek, on the other hand, may be due to Semitic influence.

\subsection{Syntax of the verb}

\subsubsection{Voice}

The active and passive voices are used much as in English. The passive occurs above all when the agent of the action cannot or is not wanted to be specified, or is less relevant. Certain verbs that are strictly speaking intransitive like $\alpha \rho \chi \omega \omega$ + genitive 'to rule over' can also be passivized.

The middle implies a particular involvement of the subject of the

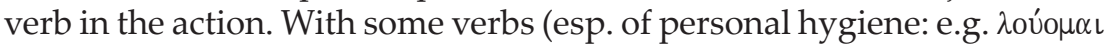
'to wash oneself') a directly reflexive relationship (identity of agent and patient) can be represented, but the reflexive pronoun (\$3.3.5) is normally used for this purpose. More commonly, the middle expresses indirect reflexivity, in which a patient distinct from the agent is present (as direct

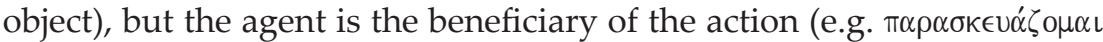
$\pi \lambda \circ$ Iov $^{\prime} \mathrm{I}$ am preparing a ship (for myself)'). Similarly middle are verbs with a causative meaning, where the agent alters his/her own mental or physical state or where the subject non-agentively undergoes an al-

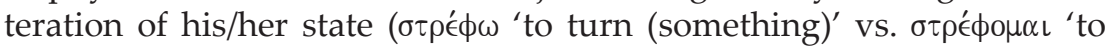

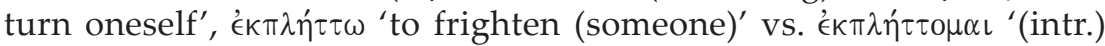


to be frightened'). Similar semantic relationships are also found in

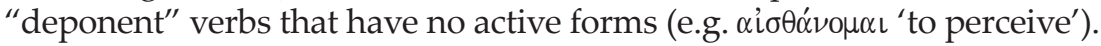

\subsubsection{Tense and aspect}

The present indicative is used not only for specific and general/habitual statements about the present of the speech act, but also for atemporal utterances. It occurs in a stylistically marked fashion with non-stative verbs as a historical present, where the visualization underscores the narrative relevance of the event portrayed in this way.

The perfect also has present reference, primarily describing the current state of the subject as the result of a past action (e.g. métாо $\theta \alpha$ 'to be convinced' as the result of past $\pi \in \epsilon^{\prime} \theta 0 \mu \alpha \iota$ 'to become convinced', $\tau$ ' $\epsilon \nu \eta \kappa \alpha$

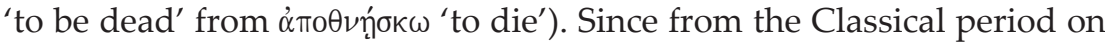
transitive-active perfects could also increasingly be formed, in which the resulting state concerns not only the subject but also the object (e.g. $\gamma^{\prime} \gamma_{\rho} \alpha \phi \alpha$ ' $\pi\left\llcorner\sigma \tau 0 \lambda \eta^{\prime} \nu\right.$ lit. 'I am one who has written a letter' > 'I have written a letter'), in the Hellenistic period the perfect developed gradually into a narrative past tense, which eventually became synonymous with the aorist and was ousted by it.

The specific or general future (from the point of view of the speech act) is indicated by the future (or the future perfect in the case of states whose present reference is expressed by the perfect). In the Classical period only rarely, but in the Hellenistic period more commonly, a paraphrase with $\mu^{\prime}{ }^{\prime} \lambda \lambda \omega+$ infinitive can be used instead ('to be about to'; only late $\theta^{\prime} \hat{\epsilon} \lambda \omega$ ' $\nu \alpha$ lit. 'to want'). The Koine also knows a colloquial futuric present.

The relationship between the past tenses (indicative) aorist and imperfect is aspectually determined. The "complexive" (or "perfective," but unrelated to the perfect) aspect of the aorist stem contrasts with the "non-complexive"/"imperfective" aspect of the present stem (pres., imperf.). The aorist expresses such past actions as are apprehended in their entirety, without their internal development being of any importance. This does not necessarily presuppose punctuality: a clause like

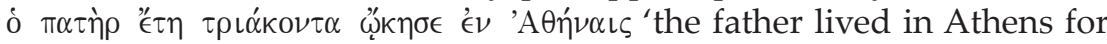

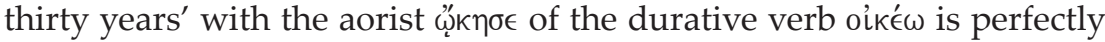
grammatical. In context, an "ingressive" interpretation of the aorist of durative verbs often results (e.g. pres. $\beta \alpha \sigma\llcorner\lambda \in \cup$ ' ‘I am king', aor. ‘ $€ \beta \alpha \sigma i ́ \lambda \epsilon u \sigma \alpha$ 'I became king').

The imperfect (and the pluperfect as "imperfect of the perfect"), in contrast, is used for a "progressive presentation," in which the action is 
perceived in its individual steps or as a development. Thus the imperfect not only describes former states or repeated events, but also portrays background events pictorially, within or following which a (foreground) event takes place. A special case is represented by the imperfectum de co$n a t u$, in which an imperfect like ' $\delta \delta$ íov is to be interpreted as 'he offered' (not 'he gave (repeatedly)').

Purely aspectual - and hence without past reference - is the use of the aorist stem in the rare "gnomic aorist" (for generalized maxims), in the non-indicative moods, and in the infinitives and participles (cf. also $\S 4.2 .4,4.2 .5)$.

\subsubsection{Moods}

Factual statements, or statements presented as factual, and questions about them are made in the indicative. The indicative imperfect or aorist (according to the aspect) is used with the modal particle $\alpha \nu$ in irrealis

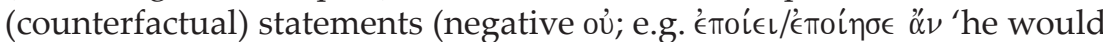

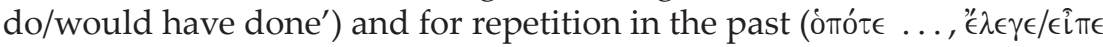
$\ddot{\alpha} \nu$ 'whenever ...., he used to say'). Without " $\alpha$, but with introductory

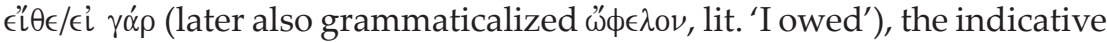
expresses an unfulfilled wish (negative $\mu$ )́).

The subjunctive originally represents an action as subjectively expected or expectable. In clauses of command (neg. $\mu$ í) the 1st person

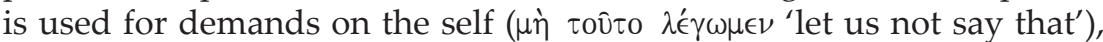
while the negated 2 nd person of the aorist subjunctive replaces a negated aorist imperative ("prohibitive" subjunctive: 'do not begin to ...'). The "deliberative" subjunctive in questions expresses the hesitant thought of

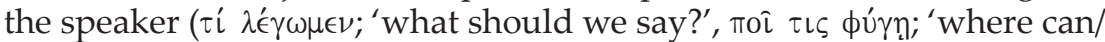
should one flee?').

The optative, qua mood of possibility, is found in main clauses in wishes assumed to be fulfillable (with or without $\epsilon^{\prime \prime} \theta \in / \epsilon i \quad \gamma \alpha \dot{\alpha} \rho$, neg. $\mu$;

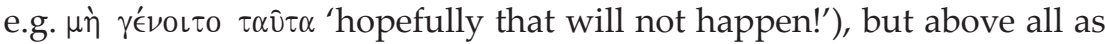
the "potential" optative with «ُ (negative oủ) to present possible actions ( $\lambda \epsilon^{\prime}$ yol $\tau \iota \varsigma \stackrel{\alpha}{\alpha} \nu$ 'one might say') or to formulate politely mitigated assertions ( Hellenistic period, it was replaced here by e.g. an indicative future.

The imperative is the mood of command (neg. $\mu$ í). However, expressions of demand can also be formulated otherwise, depending on the pragmatic situation (e.g. $\delta \in \hat{\imath} / \chi \rho \eta$ ' infinitive 'one must', verbal adjective

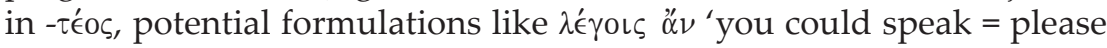


speak', oủ $\mu \eta ́$ + indicative future or subjunctive for emphatically negated future statements, etc.).

The use of moods in subordinate clauses is similar to that in main clauses, but it is also partly determined by the type of subordinate clause (cf. §4.3.2). After secondary tenses (indicative aorist, imperfect, pluperfect, historical present), a subordinate clause may contain an "oblique" optative instead of an indicative or subjunctive (but this optative too disappears in the Koine). Similarly, in the Classical period the "prospective" subjunctive is restricted to subordinate clauses (with ״ै $\nu$, in part merged

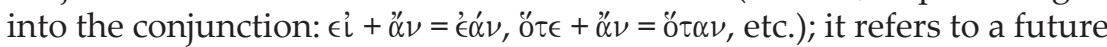

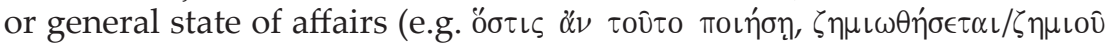
$\tau \alpha \mathrm{L}$ 'whoever does this will be punished'). For the "iterative" optative in subordinate clauses see §4.3.2.

\subsubsection{Infinitive}

Infinitives and infinitive constructions occur as independent clauses only exceptionally (e.g. as jussive infinitives in legal language). They are normally obligatory constituents depending on (a) verbs of wishing, desiring, commanding/prohibiting, ability, etc.; impersonal expressions like $\delta \in \hat{i} / \chi \rho \eta \eta^{\prime}$ 'one must'; and adjectives of ability and quality (e.g.

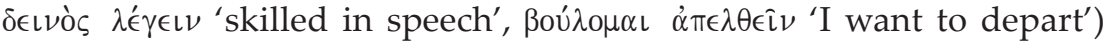
("dynamic infinitive," neg. $\mu$ )́); and (b) verbs of thinking and speaking, where they imply the actual or supposed factuality of the event less explicitly than subordinate clause constructions e.g. with ö $\tau \iota ~ ' t h a t$ '

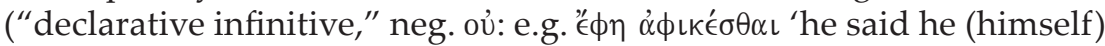
had come'; for ö $\tau$ see §4.3.2). While in the dynamic infinitive the use of the aorist or present variant is aspectually determined, and the infini-

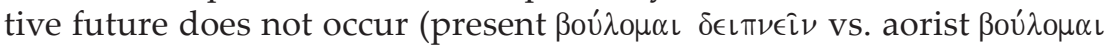

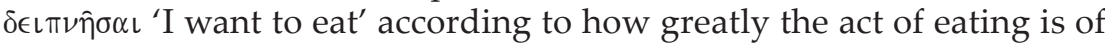
interest: §4.2.2), in the declarative infinitive the infinitive aorist mostly conveys anteriority, the infinitive present simultaneity, and the infinitive future, futurity. Already in the Koine the dynamic infinitive is in many places encroached upon by a purpose clause with i $\nu \alpha+$ subjunctive, and the declarative infinitive is increasingly replaced by ö $\tau \iota$ (later $\pi \hat{\omega} \varsigma$ ).

When and only when the subject of the declarative infinitive is different from the subject of the superordinate verb, an Accusativus cum Infinitivo construction is used in Classical Greek, with the subject of the

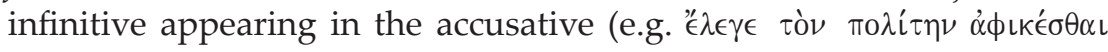


'he said that the citizen had arrived'). If this construction is passivized, a

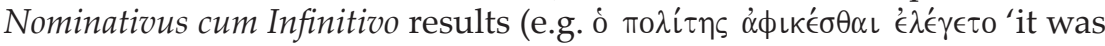
said that the citizen had arrived').

The substantivized infinitive with article is already found in the Classical period, but becomes particularly common in (literary) Hellenistic Greek. When combined with prepositions it can even replace entire subordinate clauses; its subject too is in the accusative (e.g. трò tô̂

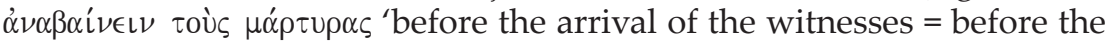
witnesses arrive'). Worth mentioning, finally, is the infinitive of purpose

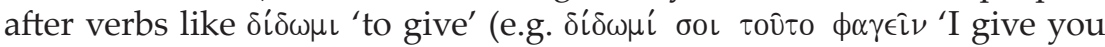
this to eat').

\subsubsection{Participles}

Participles or participial constructions occur obligatorily after verbs of knowing and perceiving, and in part also after verbs of showing and

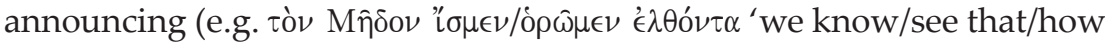
the Medes are coming' = Accusatious cum Participio; also Nominativus cum Participio when the subject of the participle and the finite verb is the

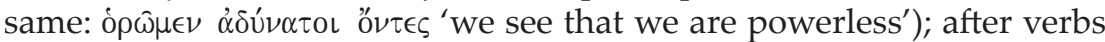
of emotion (e.g. $\chi \alpha i \rho \omega \delta\llcorner\alpha \lambda \epsilon \gamma o ́ \mu \epsilon \nu \circ \varsigma$ i $\mu \hat{\imath} \nu$ 'I am happy to talk to you'); after

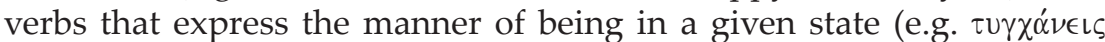
$\pi \alpha \rho \omega \nu^{\prime}$ you happen to be present'); and after "phasal" verbs (e.g. "پ $\rho \chi 0 \mu \alpha \iota /$ $\pi \alpha \dot{0} 0 \mu \alpha \iota \lambda^{\prime} \hat{\gamma}(\omega \nu$ 'I begin/stop speaking').

Even more common are Participia coniuncta. Such participles modify another concordant clause component, and various semantic shadings are possible; these are sometimes clarified by added particles (causal $\ddot{\alpha} \tau \epsilon$ )

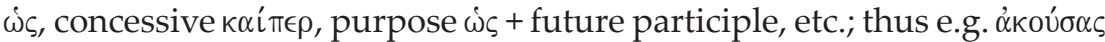

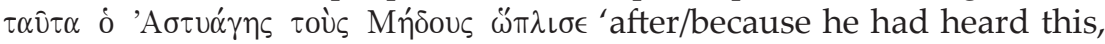
Astyages armed the Medes'). The "genitive absolute" is related, in which a construction of a noun/pronoun + participle in the genitive that is not otherwise anchored in the clause is used for adverbial expansion ( $\tau \omega v$

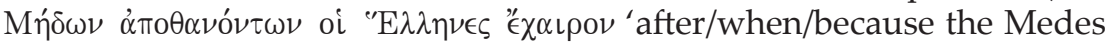
had died, the Greeks rejoiced'). Present participles convey simultaneity, aorist participles anteriority, and future participles posteriority with respect to the superordinate verb.

Like adjectives, participles can also modify a substantive (oi vôv

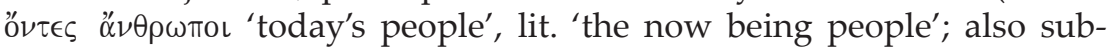
stantivized, e.g. o $\alpha \propto \rho \omega \nu$ 'the ruling = ruler'). Paraphrases of finite verbs using participles + $\epsilon^{i} \mu \mathrm{i}$ ' to be' or ' $\chi \chi \omega$ 'to have' are still exceptional in the Classical period (except in the perfect: §3.5.5). 


\subsection{Clause structure}

\subsubsection{Concord, word order, coordination}

Subject and predicate (including a predicate noun) agree, as far as possible, in person, number, case, and gender. The peculiar use of a finite verb in the singular with a subject in the neuter plural is very old ( $\tau \alpha \hat{v} \tau \alpha \kappa \alpha \lambda \alpha^{\prime}$

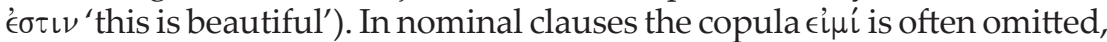

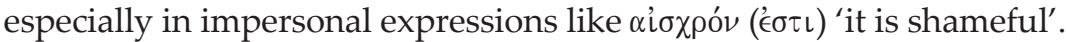

Within a clause the order of components is "free" in the sense that, say, neither the verb nor the subject always comes first. The following order of pragmatic constituents can be considered basic for Classical Greek: (1) Topic (= information that serves as an orientation framework), (2) Focus (=new information), (3) Verb (if distinct from (1) or (2)), (4) Other elements. Enclitics tend to occur in second position in the clause. However, because they often depend on the verb, the order Verb - Subject - Object becomes increasingly set during the Hellenistic period.

The concatenation of clause elements and entire clauses is only rarely asyndetic; more often one or several clause- and discourse-structuring particles are used ( $\kappa \alpha \iota^{\prime}$ 'and', $\left(\mu{ }^{\prime} \nu-\right) \delta \delta^{\prime}$ '(on the one hand) but (on the other hand)', oûv 'thus', toívuv 'therefore', $\delta \eta$ ' accordingly', etc.).

\subsubsection{Subordination}

As subordinate clauses we find subject and object clauses that are required by a verb phrase, attributive clauses (relative clauses), and adverbial clauses as free complements. Among the former are assertive clauses following verbs of saying, perceiving, etc., which are usually introduced by ö $\tau \iota$ or $\omega \varsigma$ 'that, how' (+ mood of an assertion or oblique optative: \$4.2.3)

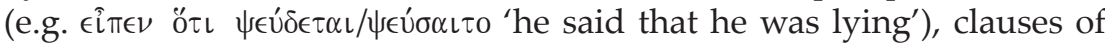
desire following verbs of caring (with ö $\pi \omega \varsigma(\mu \eta \dot{)})+$ indicative future, or in the Classical period more rarely subjunctive; e.g. '́ $\pi \iota \mu \epsilon^{\prime} \lambda \epsilon \sigma \theta \alpha \iota$ 'to see

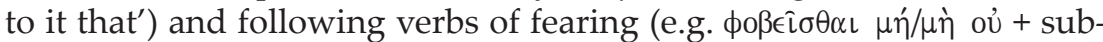
junctive/oblique optative 'to fear that/lest'), and dependent interrogative clauses (+ mood of an independent question or oblique optative: e.g.

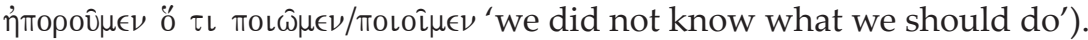

Among adverbial clauses are causal clauses (conjunctions include ö $\tau$,

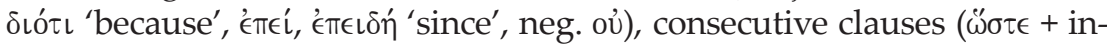
dicative (neg. oủ) for actual consequences, tential consequences), purpose clauses ( optative), conditional and concessive clauses, and temporal clauses. 
Table 17. Classical Greek conditional clause types

\begin{tabular}{|c|c|c|}
\hline & Protasis ('if ...') & Apodosis ('then ...') \\
\hline INDEFINITE & $\epsilon \hat{\imath}+$ indicative & mood according to type of statement \\
\hline Prospective & $\epsilon^{\prime} \alpha \dot{\alpha} \nu+$ subjunctive & $\begin{array}{l}\text { indicative future (or imperative) }=\text { future } \\
\text { indicative present }=\text { general }\end{array}$ \\
\hline Potential & $\epsilon \hat{\imath}+$ optative & (potential) optative $+\stackrel{\alpha}{\nu} \nu$ \\
\hline IRREALIS & $\begin{array}{l}\epsilon \hat{\imath}+\text { indicative } \\
\text { imperfect/aorist }\end{array}$ & (counterfactual) indicative imperfect/aorist $+\not \alpha \nu$ \\
\hline
\end{tabular}

Among conditional clauses (conjunction $\epsilon i$ ' if' or ' $\epsilon \dot{\alpha} \nu$, neg. $\mu \eta$ ') and the

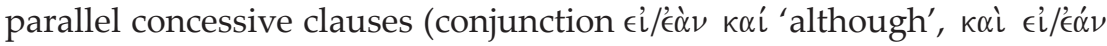
'even if') the types shown in Table 17 appear according to the degree of certainty involved. The prospective construction is also found in future

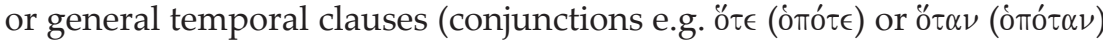

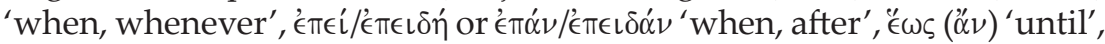

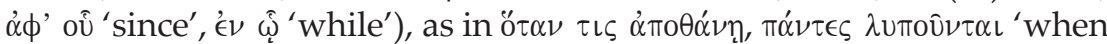
someone dies, all are saddened'. Temporal clauses referring to the past, on the other hand, are in the indicative, or with repeated events in the it-

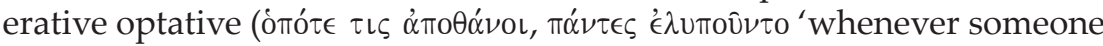
died, all were saddened'). The conjunction $\pi p$ í $\nu$ 'before' operates like the other temporal conjunctions after negative main clauses, but after posi-

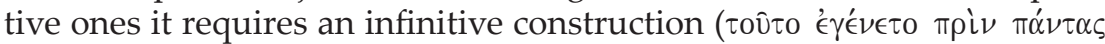
$\pi \alpha \rho \in \hat{\imath} \nu \alpha \iota_{L}$ 'this happened before all were there').

Similar to the adverbial clauses are relative clauses with conditional, causal, consecutive, or purpose (subordinate) meaning; thus, for example, conditional relative clauses too can have an indefinite, prospective, potential, or counterfactual function. However, purpose relative clauses require in the Classical period the indicative future, not, as later, the subjunctive of purpose clauses. Relative clauses without such nuances are construed like main clauses. The attraction of the relative pronoun to

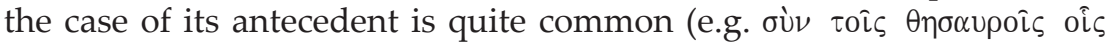

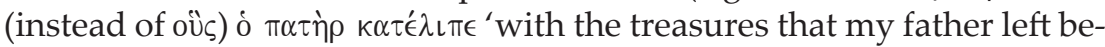
hind'). Occasionally the antecedent itself is incorporated into the relative

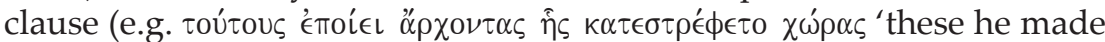
rulers of the land that he conquered').

\section{Word formation}

Only a few particularly productive types of the many derivational patterns can be mentioned here. Deverbals include the nomina agentis in 


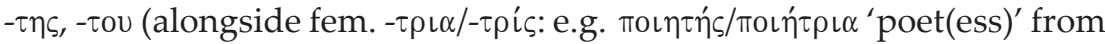

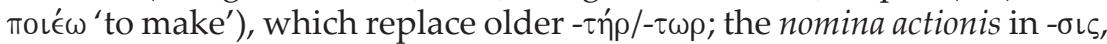

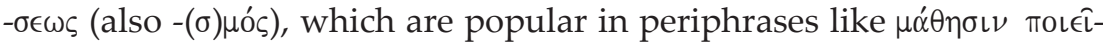
$\sigma \theta \alpha \iota=\mu \alpha \nu \theta \dot{\alpha} \nu \in \iota \nu$ 'to learn'; and the nomina rei actae in $-\mu \alpha,-\mu \alpha \tau o \varsigma$ (тоí $\mu \alpha$ 'poem'). Denominals include the abstracts in - $i \alpha /-\epsilon i \alpha$ ( $\alpha \delta \delta \kappa i \alpha$ 'injustice'

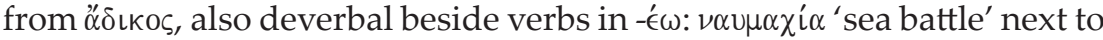

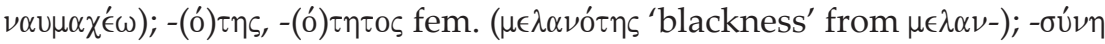

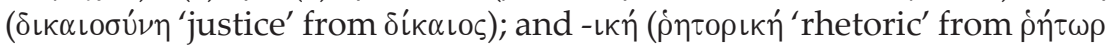
'orator'), the latter representing the substantivized feminine of one of the many denominal adjectives in -ıкós. From the Classical period on, -ıкó competes with the older but still productive relational suffix $-\operatorname{Lo\zeta }(-\alpha\llcorner O \varsigma$,

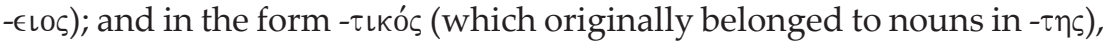
it is also used deverbally ( $\delta\left\llcorner\alpha \lambda \epsilon \kappa \tau \iota \kappa o ́ \varsigma\right.$ from $\delta\left\llcorner\alpha \lambda \lambda^{\prime} \gamma_{\gamma} \mu \alpha \iota\right.$ ' to converse').

Further important adjectival suffixes are - เvos on adjectives of ma-

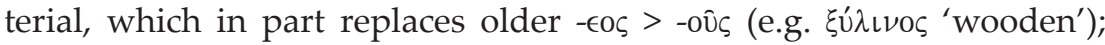

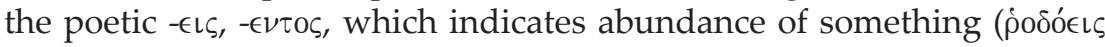

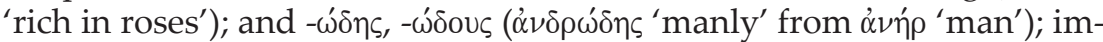

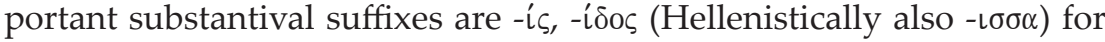
motionsfeminina (in place of the old ${ }^{*}-y a$ : §3.1.3), esp. in the suffix com-

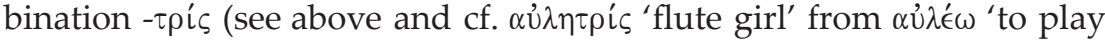

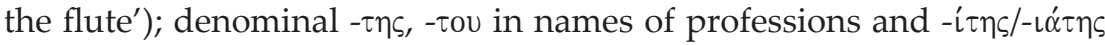

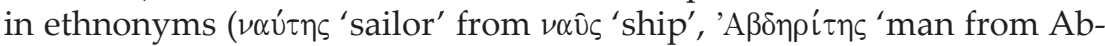

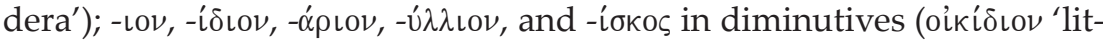
tle house' from oîкоs); and the aforementioned - $\tau$ p, which survives in names of tools ( $\lambda \alpha \mu \pi \tau \eta \dot{p} \rho$ 'lamp, torch' from $\lambda \alpha \dot{\alpha} \mu \pi \tau \omega$ 'to shine'), and from which - $\tau$ p 'prison'). Based on adjectives are adverbs in $-\omega \varsigma$ ( $\kappa \alpha \lambda \omega \varsigma$ 'beautifully').

An old verbal suffix ${ }^{*}-y(e / 0)-$, as originally added to stems in $-\llcorner\delta-/-\alpha \delta-$,

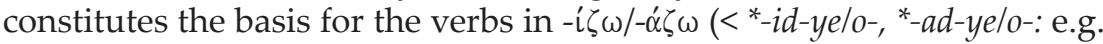
$\dot{\epsilon} \lambda \pi i \zeta \omega$ 'to hope' from ' $\lambda \lambda \pi i \varsigma^{\prime}$ 'hope'). These suffixes can then appear on the most diverse noun stems and express all sorts of semantic relations: cf. $\delta \epsilon L \pi \nu$ i $\zeta \omega$ 'to host' (from $\delta \in i \pi \nu \nu \nu$ 'meal'), $\pi \epsilon \rho \sigma i \zeta \omega$ 'to speak in Persian, to

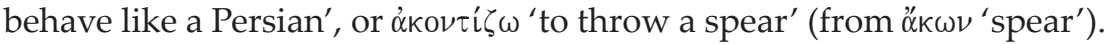

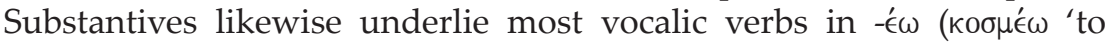

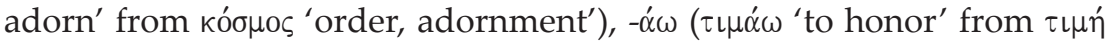

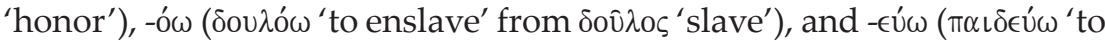

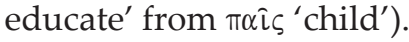

Finally, one may note the ease with which compounds are formed. Among them we find determinative compounds, in which the first component specifies a nominal second component (e.g. i $\mu$ 'i- $\theta \epsilon o \varsigma$ 'demigod'

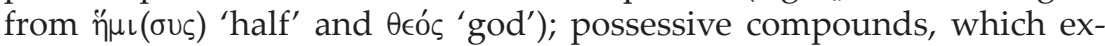

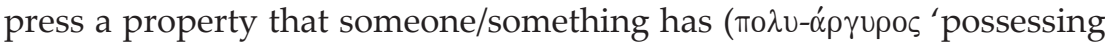




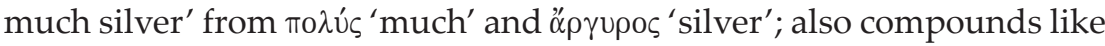

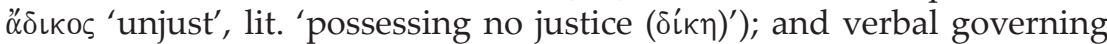
compounds with a verbal first or second component that "governs" the

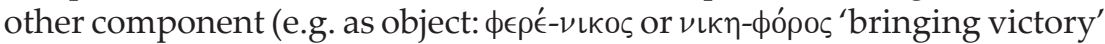

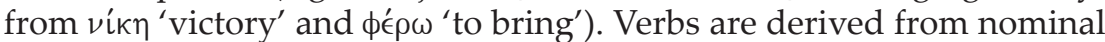
compounds on the models already described (e.g. $\psi \in \cup \delta o-\mu \alpha ́ \rho \tau u \varsigma^{\prime}$ false wit-

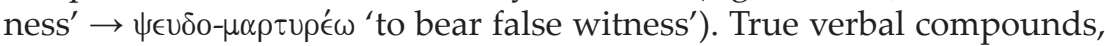
meanwhile, are only formed from verb + (in Homeric Greek often still

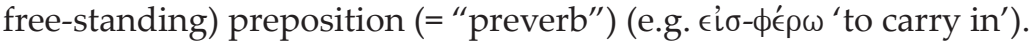

\section{Further Reading}

\section{Grammars}

Blass, Friedrich, and Albert Debrunner. 1961. A Greek Grammar of the New Testament and Other Early Christian Literature, trans. Robert W. Funk. Chicago: University of Chicago Press. Blass, Friedrich, Albert Debrunner, and Friedrich Rehkopf. 1990. Grammatik des neutestamentlichen Griechisch, 17th ed. Göttingen: Vandenhoeck \& Ruprecht.

Bornemann, Eduard, and Ernst Risch. 1978. Griechische Grammatik, 2nd ed. Frankfurt am Main: Diesterweg.

Goodwin, William Watson. 1930. A Greek Grammar, 3rd ed. rev. by Charles Burton Gulick. Boston: Ginn.

Heilmann, Luigi, and Alfredo Ghiselli. 1963. Grammatica storica della lingua greca. Turin: SEI. Jannaris, Antonius N. 1897. An Historical Greek Grammar Chiefly of the Attic Dialect as Written and Spoken from Classical Antiquity down to the Present Time. London: Macmillan.

Kühner, Raphael, Friedrich Blass, and Bernhard Gerth. 1890-1904. Ausführliche Grammatik der griechischen Sprache, 3rd ed. 4 vols. Hanover: Hahn.

Mayser, Edwin, and Hans Schmoll. 1923-34. Grammatik der griechischen Papyri aus der Ptolemäerzeit, 2nd ed. 3 vols. Berlin: de Gruyter.

Meier-Brügger, Michael. 1992. Griechische Sprachwissenschaft. 2 vols. Berlin/New York: de Gruyter.

Rix, Helmut. 1992. Historische Grammatik des Griechischen: Laut- und Formenlehre. Darmstadt: Wissenschaftliche Buchgesellschaft.

Schwyzer, Eduard, and Albert Debrunner. 1939-50. Griechische Grammatik. 2 vols. Munich: Beck.

Sihler, Andrew L. 1995. New Comparative Grammar of Greek and Latin. New York: Oxford University Press.

Smyth, Herbert Weir. 1984. Greek Grammar, 3rd ed. rev. by Gordon M. Messing. Cambridge: Harvard University Press.

Thackeray, Henry St. J. 1909. A Grammar of the Old Testament in Greek according to the Septuagint. Cambridge: Cambridge University Press. 


\section{Dictionaries}

Bauer, Walter, Kurt Aland, and Barbara Aland. 1988. Griechisch-deutsches Wörterbuch zu den Schriften des Neuen Testaments und der frühchristlichen Literatur, 6th ed. Berlin/New York: de Gruyter.

Beekes, Robert S. P. 2010. Etymological Dictionary of Greek. 2 vols. Leiden: Brill.

Chantraine, Pierre. 1968-1980. Dictionnaire étymologique de la langue grecque: Histoire des mots. 2 vols. Paris: Klincksieck.

Frisk, Hjalmar. 1960-1972. Griechisches etymologisches Wörterbuch. 3 vols. Heidelberg: Winter. Liddell, Henry George, Robert Scott, and Henry Stuart Jones. 1968. A Greek-English Lexicon, 9th ed. Rev. supp. by P. G. W. Glare (ed.), 1996. Oxford: Oxford University Press.

\section{Introduction}

Adrados, Francisco Rodríguez. 2005. A History of the Greek Language: From Its Origins to the Present, trans. Francisca Rojas del Canto. Leiden: Brill.

Bakker, Egbert J. (ed.). 2010. A Companion to the Ancient Greek Language. Malden, Mass./ Oxford: Blackwell.

Browning, Robert. 1983. Medieval and Modern Greek, 2nd ed. Cambridge: Cambridge University Press.

Bubeník, Vit. 1989. Hellenistic and Roman Greece as a Sociolinguistic Area. Amsterdam/Philadelphia: John Benjamins.

Buck, Carl Darling. 1955. The Greek Dialects. Chicago: University of Chicago Press.

Cassio, Albio Cesare (ed.). 2008. Storia delle lingue letterarie greche. Florence: Le Monnier.

Christidis, Anastasios-F. (ed.). 2007. A History of Ancient Greek: From the Beginnings to Late Antiquity. Cambridge: Cambridge University Press.

Colvin, Stephen. 2007. A Historical Greek Reader: Mycenaean to the Koiné. Oxford: Oxford University Press.

Heubeck, Alfred. 1979. Schrift. (Friedrich Matz and Hans-Günter Buchholz (eds.), Archaeologia Homerica 3/X.) Göttingen: Vandenhoeck \& Ruprecht.

Hiersche, Rolf. 1970. Grundzüge der griechischen Sprachgeschichte bis zur klassischen Zeit. Wiesbaden: Reichert.

Hoffmann, Otto, Albert Debrunner, and Anton Scherer. 1969. Geschichte der griechischen Sprache, rev. ed. 2 vols. (Sammlung Göschen.) Berlin: de Gruyter.

Horrocks, Geoffrey C. 2010. Greek: A History of the Language and its Speakers, 2nd ed. Oxford: Blackwell.

Jeffery, Lilian H. 1990. The Local Scripts of Archaic Greece, 2nd ed. ed. Alan W. Johnson. Oxford: Oxford University Press.

Meillet, Antoine. 1965. Aperçu d'une histoire de la langue grecque, 7th ed. by Olivier Masson. Paris: Klincksieck.

Palmer, Leonard R. 1980. The Greek Language. Atlantic Highlands, N.J.: Humanities Press. Repr. Norman: University of Oklahoma Press, 2000. 
Schmitt, Rüdiger. 1991. Einführung in die griechischen Dialekte, 2nd ed. Darmstadt: Wissenschaftliche Buchgesellschaft.

Thumb, Albert. 1901. Die griechische Sprache im Zeitalter des Hellenismus. Strasburg: Trübner. Thumb, Albert, Eduard Kieckers, and Anton Scherer. 1932-1959. Handbuch der griechischen Dialekte, 2nd ed. 2 vols. Heidelberg: Winter.

Wachter, Rudolf. 1996. "Alphabet, II: Das griechische Alphabet." In: Hubert Cancik and Helmuth Schneider (eds.), Der Neue Pauly: Enzyklopädie der Antike, 1: 537-547. Stuttgart: Metzler.

Woodard, Roger D. 1997. Greek Writing from Knossos to Homer. New York: Oxford University Press.

\section{Phonology}

Allen, W. Sidney. 1987. Vox Graeca: The Pronunciation of Classical Greek, 3rd ed. Cambridge: Cambridge University Press.

Bubeník, Vit. 1983. The Phonological Interpretation of Ancient Greek: A Pandialectal Analysis. Toronto: University of Toronto Press.

Devine, Andrew M., and Laurence D. Stephens. 1994. The Prosody of Greek Speech. New York: Oxford University Press.

Lejeune, Michel. 1972. Phonétique historique du mycénien et du grec ancien. Paris: Klincksieck. Karvounis, Christos. 2008. Aussprache und Phonologie im Altgriechischen. Darmstadt: Wissenschaftliche Buchgesellschaft.

Probert, Philomen. 2003. A New Short Guide to the Accentuation of Ancient Greek. London: Bristol Classical Press.

Teodorsson, Sven-Tage. 1974. The Phonemic System of the Attic Dialect 400-340 B.c. Göteborg: University of Göteborg, Institute of Classical Studies.

Teodorsson, Sven-Tage. 1977. The Phonology of Ptolemaic Koine. Göteborg: Acta Universitatis Gothoburgensis.

\section{Morphology}

Chantraine, Pierre. 1961. Morphologie historique du grec, 2nd ed. Paris: Klincksieck.

Duhoux, Yves. 2000. Le verbe grec ancien: Éléments de morphologie et de syntaxe historiques, 2nd ed. Louvain-la-Neuve: Peeters.

\section{Syntax}

Cooper, Guy L., III. 1998-2002. Attic Greek Prose Syntax. 2 vols. Ann Arbor: University of Michigan Press. 
Denniston, John D. 1954. The Greek Particles, 2nd ed. Oxford: Oxford University Press.

Dik, Helma. 1995. Word Order in Ancient Greek: A Pragmatic Account of Word Order Variation in Herodotus. Amsterdam: Gieben.

Dover, Kenneth J. 1960. Greek Word Order. Cambridge: Cambridge University Press.

Goodwin, William W. 1889. Syntax of the Moods and Tenses of the Greek Verb, 2nd ed. London: Macmillan.

Humbert, Jean. 1960. Syntaxe grecque, 3rd ed. Paris: Klincksieck.

Rijksbaron, Albert. 2002. The Syntax and Semantics of the Verb in Classical Greek: An Introduction, 3rd ed. Amsterdam: Gieben.

Wackernagel, Jacob. 1926-1928. Vorlesungen über Syntax mit besonderer Berücksichtigung von Griechisch, Lateinisch und Deutsch, 2nd ed. 2 vols. Basel: Birkhäuser.

Wackernagel, Jacob. 2009. Lectures on Syntax: With Special Reference to Greek, Latin, and Germanic, ed. and trans. David R. Langslow. Oxford: Oxford University Press.

\section{Word formation}

Chantraine, Pierre. 1933. La formation des noms en grec ancien. Paris: Champion.

Debrunner, Albert. 1917. Griechische Wortbildungslehre. Heidelberg: Winter.

Risch, Ernst. 1974. Wortbildung der homerischen Sprache, 2nd ed. Berlin/New York: de Gruyter. 
